\title{
Experimental Plan for the Vermiculite Study
}

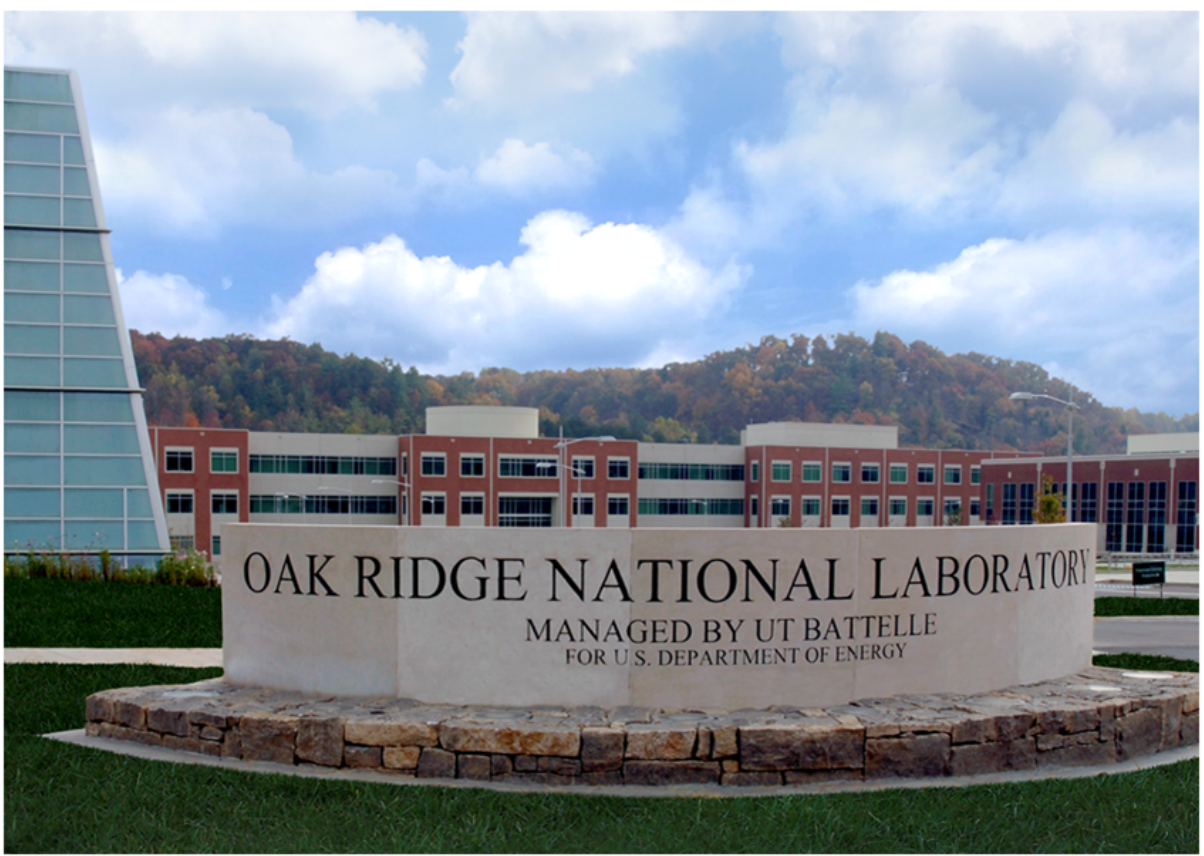

Prateek Shrestha, Ph.D.

Mark Ternes

Jason DeGraw, Ph.D.

Date: July 2021 


\title{
DOCUMENT AVAILABILITY
}

Reports produced after January 1, 1996, are generally available free via US Department of Energy (DOE) SciTech Connect.

Website www.osti.gov

Reports produced before January 1, 1996, may be purchased by members of the public from the following source:

\author{
National Technical Information Service \\ 5285 Port Royal Road \\ Springfield, VA 22161 \\ Telephone 703-605-6000 (1-800-553-6847) \\ TDD 703-487-4639 \\ Fax 703-605-6900 \\ E-mail info@ntis.gov \\ Website http://classic.ntis.gov/
}

Reports are available to DOE employees, DOE contractors, Energy Technology Data Exchange representatives, and International Nuclear Information System representatives from the following source:

Office of Scientific and Technical Information

PO Box 62

Oak Ridge, TN 37831

Telephone 865-576-8401

Fax 865-576-5728

E-mail reports@osti.gov

Website http://www.osti.gov/contact.html

This report was prepared as an account of work sponsored by an agency of the United States Government. Neither the United States Government nor any agency thereof, nor any of their employees, makes any warranty, express or implied, or assumes any legal liability or responsibility for the accuracy, completeness, or usefulness of any information, apparatus, product, or process disclosed, or represents that its use would not infringe privately owned rights. Reference herein to any specific commercial product, process, or service by trade name, trademark, manufacturer, or otherwise, does not necessarily constitute or imply its endorsement, recommendation, or favoring by the United States Government or any agency thereof. The views and opinions of authors expressed herein do not necessarily state or reflect those of the United States Government or any agency thereof. 
Buildings and Transportation Science Division

\title{
EXPERIMENTAL PLAN FOR THE VERMICULITE STUDY
}

\author{
Prateek Shrestha, Ph.D. \\ Mark Ternes \\ Jason DeGraw, Ph.D.
}

Date Published: July 2021 (DRAFT)

Prepared by

OAK RIDGE NATIONAL LABORATORY

Oak Ridge, TN 37831-6283

managed by

UT-BATTELLE, LLC

for the

US DEPARTMENT OF ENERGY

under contract DE-AC05-00OR22725 


\section{CONTENTS}

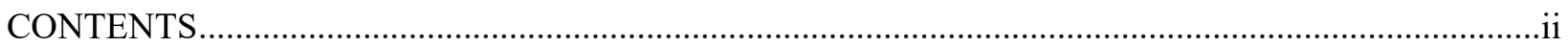

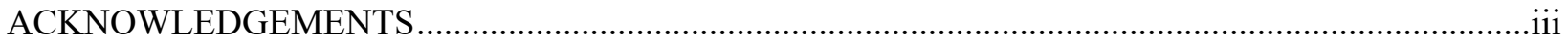

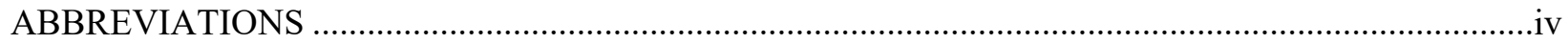

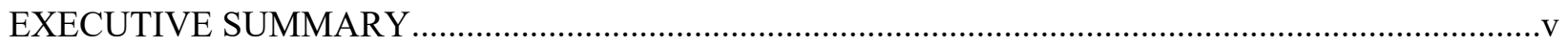

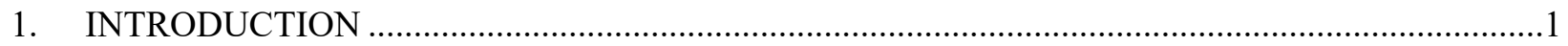

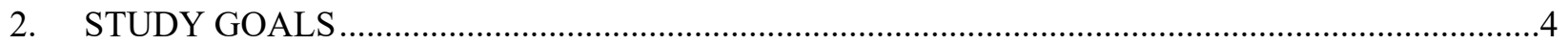

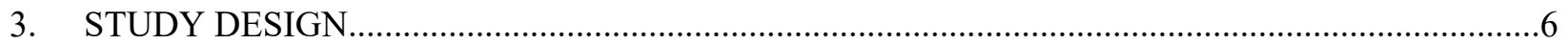

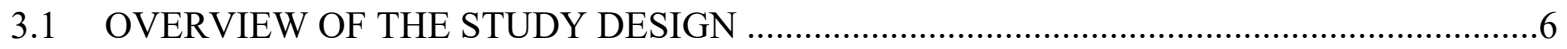

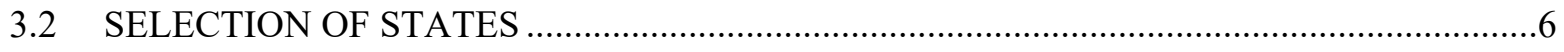

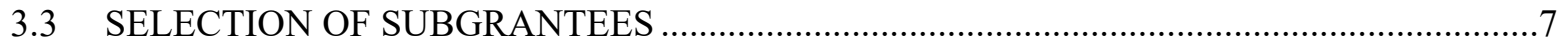

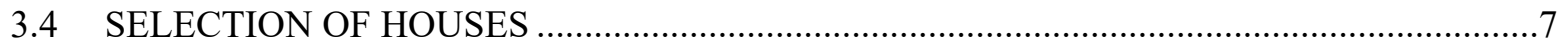

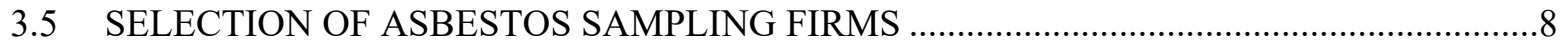

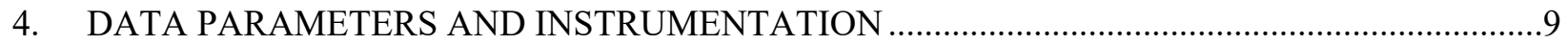

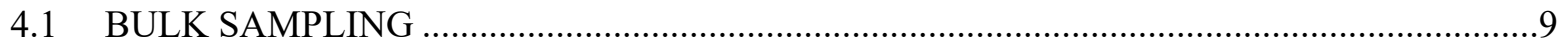

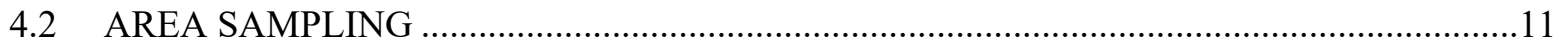

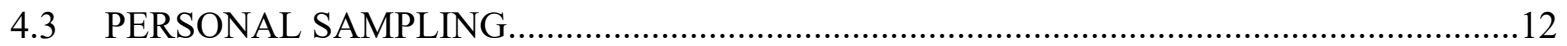

4.4 SURFACE WIPE SAMPLING FOR SETTLED ASBESTOS …........................................13

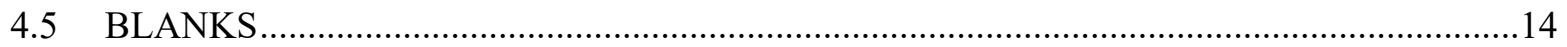

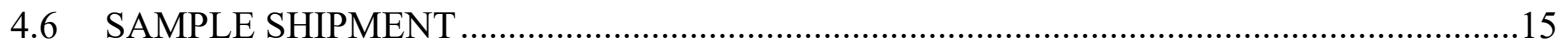

4.7 CALIBRATIONS AND QUALITY ASSURANCE OF INSTRUMENTATION DATA........15

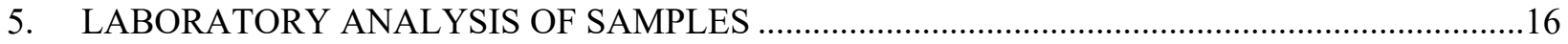

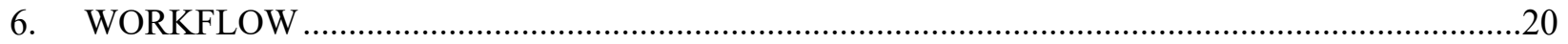

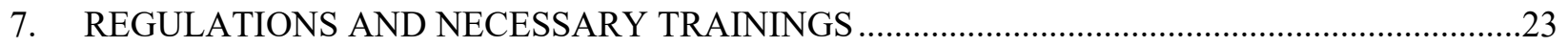

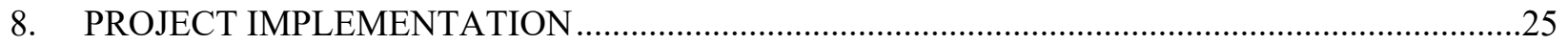

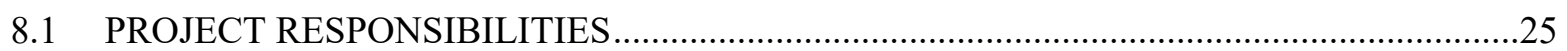

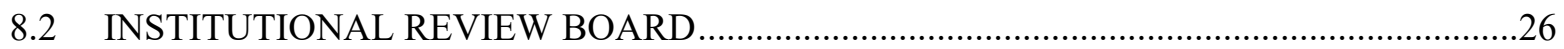

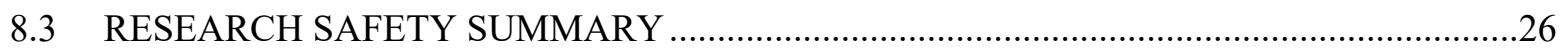

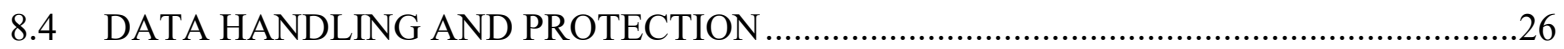

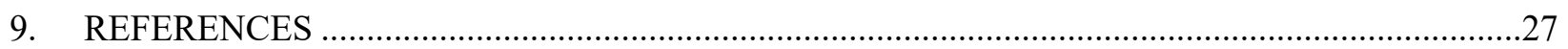

APPENDIX A. PRE-WEATHERIZATION ACTIVITY WALKTHROUGH

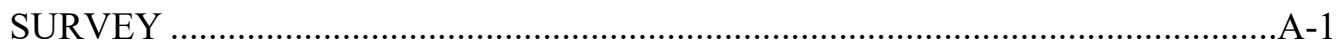

APPENDIX B. POST-WEATHERIZATION ACTIVITY SURVEY ….............................

APPENDIX C. SAMPLE NOMENCLATURE AND SAMPLE ID FORM ....................... -1

APPENDIX D. SAMPLING PROCEDURES FOR WIPE SAMPLING ...........................D-1 


\section{ACKNOWLEDGEMENTS}

Several subject matter experts, commercial service providers, and government program officers provided valuable contributions in the drafting of this experimental plan. The authors are grateful to the following individuals and groups:

Bill Eckman, Mini Malhotra, Chadwick Replogle, Julia Hancock, and Leigh Greeley ORNL

Blake Worthington

Tennessee Housing Development Agency

State of Tennessee

Christopher R. Johnson, PG and Ron Francis

Resolution, Inc.

Dave Hogue

The Environmental Institute

Geoff Wilcox

Office of Economic Opportunity

State of Vermont

Josh Silverman

EMSL Analytical, Inc.

Marcia Lemon, Gary Grubb, Sam Hall, and Shari Shephard

Department of Public Health and Human Resources

State of Montana

Megan Meadows and Scott Kashuba

Home Weatherization Assistance Program

State of Ohio

Michael Pererson, Christine Askew, William Orthwein, and Shawn Greene

US Department of Energy

Mick Prince and Wayne Hartel

Department of Commerce

State of Illinois

Rory Hoffman and Bruce Hagen

Department of Commerce

State of North Dakota

Seth Kolodzeijski and Laura Viik

Department of Commerce

State of Washington

Todd C. Hobson

Clay Point Associates, Inc.

Vermont 
ABBREVIATIONS

$\begin{array}{ll}\text { ACM } & \text { Asbestos Containing Material } \\ \text { AHERA } & \text { Asbestos Hazard Emergency Response Act } \\ \text { AIHA } & \text { American Industrial Hygiene Association } \\ \text { ASTM } & \text { American Society for Testing and Materials } \\ \text { CFR } & \text { Code of Federal Regulations } \\ \text { COC } & \text { Chain of Custody } \\ \text { DOE } & \text { Department of Energy } \\ \text { EPA } & \text { Environmental Protection Agency } \\ \text { f/cc } & \text { Fibers per cubic centimeter } \\ \text { lpm } & \text { Liters per minute } \\ \text { NIOSH } & \text { National Institute for Occupational Safety and Health } \\ \text { NOAA } & \text { National Oceanic and Atmospheric Administration } \\ \text { NVLAP } & \text { National Voluntary Laboratory Accreditation Program } \\ \text { ORNL } & \text { Oak Ridge National Laboratory } \\ \text { OSHA } & \text { Occupational Safety and Health Administration } \\ \text { PACM } & \text { Presumed Asbestos Containing Material } \\ \text { PCM } & \text { Phase Contrast Microscopy } \\ \text { PLM } & \text { Polarized Light Microscopy } \\ \text { PPE } & \text { Personal Protective Equipment } \\ \text { s/mm } & \\ \text { sq. ft. } & \text { Structures per square millimeter (of sampler filter area) } \\ \text { TEM } & \text { Square feet } \\ \text { TWA } & \text { Transmission Electron Microscopy } \\ \text { US EPA } & \text { Time weighted average } \\ \text { USGS } & \text { United States Environmental Protection Agency } \\ \text { WAP } & \text { United States Geological Survey } \\ \text { WPN } & \text { Weatherization Assistance Program } \\ & \text { Weatherization Program Notice }\end{array}$




\section{EXECUTIVE SUMMARY}

Houses in which vermiculite insulation, which can contain asbestos, is present are often deferred under the U.S. Department of Energy (DOE) Weatherization Assistance Program (WAP) because of uncertainty in how to safely weatherize such houses from a client and worker perspective and the potential costs associated with alternative approaches. Recognizing this situation, the DOE tasked the Oak Ridge National Laboratory (ORNL) to perform a research project that scientifically identifies the asbestos contamination and exposure risks in weatherizing houses with existing vermiculite insulation.

Current approaches being used by various states (Grantees), and local weatherization agencies (Subgrantees) within each state, to weatherize houses with existing vermiculite insulation were identified as part of the development of this experimental plan based on a review of Grantee Health and Safety Plans and communications with weatherization program staff from eight states. Other than deferral, these approaches include the following:

1. Abating (i.e., removing) the existing vermiculite insulation using funding sources other than WAP (e.g., state funds, utility funds, the Zonolite Attic Insulation Trust Fund, and possibly homeowner contributions) because abatement is not allowed using WAP funds per Weatherization Program Notice (WPN) 17-7.

2. Weatherizing the house as normal after testing reveals that the vermiculite insulation contains less than $1 \%$ asbestos.

3. Avoiding areas of the house where vermiculite insulation is installed and weatherizing the remaining areas of the house as normal.

4. Blowing cellulose or other insulation over the existing vermiculite insulation.

5. Weatherizing the areas of the house where vermiculite insulation is installed using unique/alternative approaches developed specifically for that house.

Blower door testing is also impacted by the presence of vermiculite insulation due to the concern of potentially contaminating the living spaces with airborne asbestos fibers. Some states address this by performing positive-pressure blower door tests (as opposed to negative-pressure blower door tests), whereas other states prohibit blower door testing entirely when loose vermiculite insulation is present anywhere in the house.

This research project will focus on gathering data on house occupant and weatherization worker exposures to asbestos before, during, and after the weatherization of the houses containing vermiculite insulation using four out of five approaches identified above (not considering complete abatement), combined with the policy on blower door testing. Abatement of the existing vermiculite insulation will not be studied because it is not allowed using WAP funding per WPN 17-7 and, thus, is not a sustainable approach for WAP.

It is envisioned that 50-100 houses will be monitored from 3-5 states and 2-3 Subgrantees per Grantee under this study. We have identified five states that we are interested in working with based on their policies and approaches to weatherizing houses with vermiculite insulation. In identifying these states, an effort was made to identify states that used a variety of the approaches to be studied. Table ES 1 identifies the five states along with the approaches that they use. 
Table ES 1. States and their approaches to weatherizing houses with vermiculite insulation.

\begin{tabular}{|c|c|c|c|c|c|}
\hline Approaches & Wisconsin & Vermont & Illinois & $\begin{array}{l}\text { North } \\
\text { Dakota }\end{array}$ & Ohio \\
\hline \multicolumn{6}{|l|}{ Weatherization: } \\
\hline $\begin{array}{l}\text { Weatherize as normal if testing indicates that the } \\
\text { vermiculite insulation contains }<1 \% \text { asbestos }\end{array}$ & & & & & $x$ \\
\hline $\begin{array}{l}\text { Avoid areas of the house with vermiculite but } \\
\text { weatherize the rest of the house as normal }\end{array}$ & & & $x$ & & $x$ \\
\hline $\begin{array}{l}\text { Blowing a layer of cellulose over the vermiculite } \\
\text { insulation }\end{array}$ & $x$ & & & $x$ & \\
\hline $\begin{array}{l}\text { Weatherize the areas of the house with } \\
\text { vermiculite using unique/alternative approaches }\end{array}$ & & $x$ & & & \\
\hline \multicolumn{6}{|l|}{ Blower Door Test: } \\
\hline Positive-pressure blower door test & $x$ & & $x$ & & $x$ \\
\hline Negative-pressure blower door test & & & & $x$ & \\
\hline No blower door test & & $x$ & & & \\
\hline
\end{tabular}

Two to three Subgrantees will be selected from each state based on the number of houses that the Subgrantee typically weatherizes in a year that has vermiculite insulation present, the approaches that they use in such houses, the Subgrantee's capacity to implement the study (e.g., time to coordinate with the house occupants, flexibility in scheduling houses for testing and weatherization, asbestos training and credentials), and recommendations from state staff. Subcontracts will be established with the chosen Subgrantees to compensate them for their time in implementing the study.

The houses used in the study will be limited to single-family houses or side-by-side duplexes (mobile houses and multifamily buildings will not be studied) and those eligible to receive WAP services. These houses will be drawn from the Subgrantee's population of houses on a rolling-basis (i.e., houses with vermiculite insulation will be brought into the study as they are encountered by the Subgrantees on a chronological order). Gift cards will be given to the homeowners as compensation for participating in the study. The number of houses that will be monitored was estimated as follows:

- To evaluate the impact of weatherization activities alone without considering the impact of blower door testing, it was assumed that five houses could be monitored from each of the two to three Subgrantees from each of five states $(5 \times 2 \times 5=50$ in case of 2 Subgrantees per state, $5 \times 3$ $\mathrm{x} 5=75$ in case of three Subgrantees per state).

- For evaluating the impact solely due to pressurized blower door testing, it was assumed that five houses could be monitored from each of two agencies from three of the same five states $(5 \times 2 \times 3$ $=30$ ). Note that these houses could be a subset of the same 50-75 houses monitored above, or could be different than those 50-75 houses, making the total number of houses being monitored to roughly 100. Although it is seen from Table ES 1 that North Dakota currently allows negative pressure blower door tests, we will not be involved with this type of testing and will only monitor the houses for weatherization activities.

The following measurements will be made in each house:

- Pre- and post- weatherization activity surface wipes on three to five hard surfaces within the houses (e.g., floors, countertops) to establish baseline asbestos levels and types of asbestos found in the samples (there are six major types of asbestos commonly found in engineered products, namely, Chrysotile, Amosite, Crocidolite, Tremolite, Actinolite and Anthophyllite) . 
- Pre- and post-weatherization activity indoor air (area) samples from three to five locations in the living space of the house to determine indoor air asbestos concentrations.

- Personal air samples collected from the breathing zone of weatherization workers (at least $25 \%$ of the workforce involved) during-weatherization activity to determine the airborne asbestos levels each worker is exposed to during weatherization.

- Asbestos concentrations from three to five bulk samples of the vermiculite insulation found in the house to determine if the vermiculite insulation contains asbestos, and whether the asbestos found in the vermiculite insulation, if any, can be attributed to the vermiculite mine located in Libby, Montana.

These samples will be analyzed by one commercial laboratory contracted with to provide analytical services. The selected laboratory will be compliant with the Asbestos Hazard Emergency Response Act of $1986^{1}$ (AHERA) requirements for analytical laboratories and accredited under the American Industrial Hygiene Association (AIHA) ${ }^{2}$ and the National Voluntary Laboratory Accreditation Program ${ }^{3}$ (NVLAP).

In addition, data will be collected on key house characteristics pertinent to this study. Data related to the location and/or local weather will also be collected as needed from public sources (e.g., the National Oceanic and Atmospheric Administration, the United States Geological Survey).

It is anticipated that the measurements listed above will be made on at least two separate days because of the length of time needed to make the indoor air samples ( 5 hours), the time required to perform the weatherization activity being studied, and other logistical considerations. For example, when blowing cellulose over vermiculite insulation in the attic and pressurized blower door tests are being studied in the same house, pre-weatherization activity data will be collected and the weatherization work (blowing cellulose and/or blower door test) will be performed the first day and post-weatherization data will be collected the second day. For the other three approaches being studied, there will likely be at least several days between when the pre- and post-weatherization activity measurements are made because of the length of time needed to complete the house weatherization activity.

Implementation of this experimental plan will vary in each state depending on how WAP itself is implemented in that state, the specific vermiculite-related approaches being studied, the capabilities of the Subgrantees selected for participation in the study, the availability of a research organization to help implement the study, and other factors. An implementation plan will be developed for each state based on these factors. An accredited asbestos contractor or research organization (preferably local to the state or region) and the two to three Subgrantees from each state will be contracted with to help collect data for the study within each state.

In the event that the blower door test or weatherization activity performed in the house exacerbates the airborne asbestos levels in the living spaces, a cleanup of the living spaces of the house will be performed using the study funds. Following cleanup work completion, air sampling will be performed using AHERA transmission electron microscopy analysis confirming that the living space is returned to the standard clearance level for re-occupation of less than $70 \mathrm{~s} / \mathrm{mm}^{2}$. To ensure the safety of all human subjects, we will require all the participating households to be temporarily relocated throughout the length of our study activities in their house, and will be compensated for the same using our study funds.

\footnotetext{
${ }^{1}$ The Asbestos Hazard Emergency Response Act (AHERA) requires local educational agencies to inspect their school buildings for asbestos-containing building material, prepare asbestos management plans and perform asbestos response actions to prevent or reduce asbestos hazards (https://www.epa.gov/asbestos/asbestos-laws-andregulations\#ahera)

${ }^{2}$ https://www.aiha.org/

${ }^{3}$ The National Voluntary Laboratory Accreditation Program (NVLAP) provides third-party accreditation to testing and calibration laboratories in response to legislative actions or requests from government agencies or private-sector organizations. NVLAP-accredited laboratories are assessed against the management and technical requirements published in the International Standard, ISO/IEC 17025:2017 (https://www.nist.gov/nvlap)
} 


\section{INTRODUCTION}

Vermiculite is a naturally occurring mineral that was historically mined with one of the end applications being a thermal insulation material. When heated to a critical temperature, vermiculite expands many times its original volume and forms a fibrous mesh with good thermal insulation and fire retarding properties. These properties coupled with low cost made vermiculite a popular building insulation material in the early 1920s. Later, it was discovered that almost $70 \%$ of the vermiculite being used in US buildings as thermal insulation material was contaminated with friable asbestos fibers, mostly originating from the Libby mine in Montana [1]. After several research findings related to asbestos exposure risks with vermiculite attic insulation were published, builders stopped using vermiculite as insulation material in houses built after 1990 .

The US Environmental Protection Agency (US EPA) recommends that vermiculite insulation found in a house should be assumed to be contaminated with asbestos and treated accordingly unless testing indicates otherwise. EPA further recommends that vermiculite insulation be left undisturbed unless removed by trained professionals and recommends abatement (i.e., removal) of vermiculite insulation using a certified professional before any renovation or retrofit activities begins in buildings.

The Occupational Health and Safety Administration (OSHA) has set permissible exposure limits in occupational exposures to any type of asbestos at an 8-hour time-weighted average permissible exposure limit of 0.1 fiber per cubic centimeter $(\mathrm{f} / \mathrm{cc})$ and an excursion level for 30 -minute time-weighted average at $1.0 \mathrm{f} / \mathrm{cc}$ [2] due to the known risks of asbestos exposure that can lead to respiratory health issues like asbestosis, mesothelioma, and lung cancer [3]-[7]. Among the six major types of asbestos commonly found in commercial products and regulated by the US EPA and OSHA (Table 1 below), the Tremolite and Actinolite types of asbestos are the types existing as contaminants in the Libby vermiculite [8].

Table 1. Six main types of regulated asbestos minerals [9].

\begin{tabular}{|c|c|c|c|c|c|}
\hline $\begin{array}{l}\text { Common } \\
\text { Name }\end{array}$ & Form & CAS No. & Synonyms & Idealized Chemical Formula & Color \\
\hline Chrysotile & Serpentine & $12001-29-5^{*}$ & $\begin{array}{l}\text { Serpentine } \\
\text { asbestos; white } \\
\text { asbestos }\end{array}$ & {$\left[\mathrm{Mg}_{3} \mathrm{Si}_{2} \mathrm{O}_{5}(\mathrm{OH})_{4}\right]_{\mathrm{n}}$} & $\begin{array}{l}\text { White, } \\
\text { grey, } \\
\text { green, } \\
\text { yellowish }\end{array}$ \\
\hline Crocidolite & Amphibole & $12001-28-4 *$ & Blue asbestos & {$\left[\mathrm{NaFe}_{2}+3 \mathrm{Fe}_{3}+2 \mathrm{Si}_{8} \mathrm{O}_{22}(\mathrm{OH})_{2}\right]_{\mathrm{n}}$} & $\begin{array}{l}\text { Lavender, } \\
\text { blue } \\
\text { green }\end{array}$ \\
\hline Amosite & Amphibole & $12172-73-5^{*}$ & Brown asbestos & {$\left[\left(\mathrm{Mg}_{2} \mathrm{Fe}_{2}+\right) 7 \mathrm{Si}_{8} \mathrm{O}_{22}(\mathrm{OH})_{2}\right]_{\mathrm{n}}$} & $\begin{array}{l}\text { Brown, } \\
\text { grey, } \\
\text { greenish }\end{array}$ \\
\hline Anthophyllite & Amphibole & $17068-78-9 *$ & $\begin{array}{l}\text { Ferroanthophyllite; } \\
\text { azbolen asbestos }\end{array}$ & {$\left[\left(\mathrm{Mg}, \mathrm{Fe}_{2}+\right) 7 \mathrm{Si}_{8} \mathrm{O} 22(\mathrm{OH})_{2}\right] \mathrm{n}$} & $\begin{array}{l}\text { Grey, } \\
\text { white, } \\
\text { brown- } \\
\text { grey, } \\
\text { green }\end{array}$ \\
\hline Actinolite & Amphibole & $12172-67-7^{*}$ & Unspecified & $\begin{array}{l}\mathrm{Ca} 2(\mathrm{Mg}, \\
\left.\mathrm{Fe}_{2}+5 \mathrm{Si}_{8} \mathrm{O} 22(\mathrm{OH})_{2}\right]_{\mathrm{n}}\end{array}$ & Green \\
\hline Tremolite & Amphibole & $14567-73-8^{*}$ & $\begin{array}{l}\text { Silicic acid; } \\
\text { calcium } \\
\text { magnesium salt } \\
(8: 4)\end{array}$ & {$\left[\mathrm{Ca}_{2} \mathrm{Mg} 5 \mathrm{Si}_{8} \mathrm{O}_{22}(\mathrm{OH})_{2}\right]_{\mathrm{n}}$} & $\begin{array}{l}\text { White to } \\
\text { pale } \\
\text { green }\end{array}$ \\
\hline $\begin{array}{l}{ }^{*} \text { Identified as } \\
\text { NR, not report }\end{array}$ & $\begin{array}{l}\text { isbestos by } \mathrm{C} \\
\mathrm{d}\end{array}$ & AS Registry & & & \\
\hline
\end{tabular}


Low-income households have been benefiting from the US Department of Energy (DOE) Weatherization Assistance Program (WAP) since 1976 [10]. Under this program, single-family and multifamily buildings occupied by low-income households can receive a variety of weatherization measures to reduce energy use and costs such as attic, wall, and floor insulation; air-tightening the building shell; sealing the air distribution systems; heating equipment upgrades; window replacements; and energy-efficient lighting. However, houses in which vermiculite insulation is present are often automatically deferred under WAP because of uncertainty in how to safely weatherize such houses from a client and worker perspective and the potential costs associated with alternative approaches. Recognizing this situation, DOE tasked the Oak Ridge National Laboratory (ORNL) to perform a research project that scientifically identifies the asbestos exposure risks in weatherizing houses with existing vermiculite insulation using weatherization techniques currently employed by the states and Subgrantees implementing the program.

Weatherization Program Notice (WPN) 17-7 provides health and safety guidance relevant to vermiculite insulation that includes

- When vermiculite is present, assume it contains asbestos unless testing determines otherwise.

- Do not perform a blower door test if it will disturb the vermiculite.

- Use proper respiratory protection while in areas containing vermiculite.

- Encapsulation by an appropriately trained asbestos control professional is allowed.

- Removal is not allowed using health and safety or other WAP funds.

Current approaches being used by the states and Subgrantees to weatherize houses with existing vermiculite insulation were identified as part of the development of this experimental plan based on a review of Grantee Health and Safety Plans and communications with weatherization program staff from eight states.

The approaches that were identified as current practices by the states include the following:

1. Automatic deferral from WAP qualification upon identification of vermiculite in the house, i.e., no weatherization is performed on the house.

2. Abatement of the existing vermiculite insulation is performed using funding sources other than WAP. Abatement is not allowed using WAP funds per WPN 17-7, so other funding sources are used such as state funds, utility funds, the Zonolite Attic Insulation Trust Fund [11], and possibly homeowner contributions. Asbestos professionals perform the abatement work. The house is weatherized as normal (including blower door testing) following Grantee WAP procedures once clearance testing has indicated that the vermiculite insulation has been completely removed. Abatement is usually restricted to attics because it is much more expensive to remove vermiculite insulation found in a wall than in an attic. As a special case, abatement may also be performed if the vermiculite insulation covers an area of less than 10 sq. $\mathrm{ft}$. (e.g., in the middle of a basement floor) because of reduced costs (e.g., small amounts of material involved, permits are not needed).

3. The house is weatherized as normal (including blower door testing) following Grantee WAP procedures if testing performed by an accredited laboratory shows that the vermiculite insulation contains less than $1 \%$ asbestos.

4. The areas of the house where vermiculite insulation is not present are weatherized as normal following Grantee WAP procedures while the areas known to have vermiculite insulation are avoided so that the material is not disturbed. This usually means that insulation is not added to the areas with vermiculite insulation and air sealing work is not performed in these areas, although other measures may also be impacted. Additionally, blower door testing may or may not be performed. 
5. The existing vermiculite insulation in the attic is covered from the top by blowing cellulose insulation over the vermiculite insulation. Additionally, air sealing work in the area where the vermiculite insulation is present and blower door testing may or may not be performed.

6. The areas of the house where vermiculite insulation is present are weatherized using unique/alternative insulation and air sealing techniques developed specifically for the house that do not disturb the vermiculite. For example, the ceiling of an addition may be insulated by adding rigid insulation to the underside of the ceiling (i.e., the inside the house) rather than installing insulation above the ceiling in the attic where the vermiculite insulation is present. As another example, insulation may be installed above a floored attic if the vermiculite insulation is located in the cavity space below the attic flooring (i.e., the space between the ceiling and the flooring installed above the attic floor joists). This approach is usually applicable on a very limited basis. Additionally, blower door testing may or may not be performed.

Blower door testing is also impacted by the presence of vermiculite insulation. Blower door testing quantifies the effective leakage area of the building envelope and assists in identifying air leakage pathways in houses that may result in energy loss. When the presence of vermiculite insulation is confirmed in a house, a blower door test may not be performed or the test may be conducted by pressurizing the house rather than depressurizing it to prevent asbestos from being drawn into the living spaces of the house.

An initial literature review and communications with stakeholders indicated that there is little scientific evidence demonstrating efficacy of the approaches outlined above when undertaken in houses with existing vermiculite insulation during the process of weatherization to ensure the safety of the house occupants or the weatherization workers. Many states currently allow positive-pressure blower door tests as part of the initial energy audit of the house before conducting weatherization activities, but there has been no comprehensive studies on whether or not this approach contributes to a rise in airborne asbestos fiber concentrations in the living spaces of the houses with existing vermiculite insulation.

Hence, this research project will focus on gathering data on house occupant and weatherization worker exposures to asbestos before, during, and after weatherization-related work is performed in houses containing vermiculite insulation using five approaches identified above in addition to the impact of positive-pressure blower door testing on indoor asbestos levels. Abatement of the existing vermiculite insulation will not be studied because it is not allowed using WAP funding per WPN 17-7 and, thus, is not a sustainable approach for WAP. The experimental evidence that this study will provide will pave a path in potentially identifying cost-effective ways to carry out safe weatherization practices in houses with existing vermiculite insulation, so that such houses do not have to be deferred or have to resort to the very costly option of complete abatement of the vermiculite insulation. 


\section{STUDY GOALS}

There are two main goals of this study.

1. The first goal is to determine the impact, if any, that positive-pressure blower door tests and weatherization work have on indoor asbestos levels in houses with existing vermiculite insulation. This portion of the study will be conducted by taking surface wipe samples of settled dust and indoor air samples before these activities are performed to establish a baseline average concentration of asbestos fibers in the living spaces of the houses. Similar measurements will be taken in the same locations after these activities are performed to measure the change, if any, in asbestos levels.

2. The second goal is to measure the exposure levels of weatherization workers while they perform positive-pressure blower door tests or undertake weatherization activities in houses with existing vermiculite insulation. This will be done by performing personal air sampling from the breathing zones of at least $25 \%$ of the weatherization worker workforce using a portable personal air sampling apparatus fitted to the worker's body.

The major questions to be addressed by the study are as follows:

1. Study on potential asbestos exposures of house occupants before and after positive-pressure blower door testing and weatherization work are performed in houses with vermiculite insulation:

a. What are the types and concentrations of asbestos found in the settled dust on horizontal surfaces in the living spaces of the houses before the commencement of positive-pressure blower door testing or weatherization activities?

b. Is the source of any asbestos found in the settled dust of the house prior to positivepressure blower door testing or weatherization activity attributable to the vermiculite insulation that exists in the house? Identification of asbestos types among the six commonly found types (see Table 1) will help associate the sampled asbestos with the sources in the house. For example, confirmation of Tremolite or Actinolite asbestos in the surface samples would suggest that the asbestos fibers originated from the vermiculite insulation, whereas the presence of only Chrysotile asbestos would suggest other origins like wall or plumbing insulation.

c. What are the types and concentrations of asbestos found in the settled dust on the previously sampled horizontal surfaces after positive-pressure blower door testing or weatherization activities are performed?

d. Does the type and concentration of asbestos found in the settled dust on the previously sampled horizontal surfaces indicate that positive-pressure blower door testing or weatherization activity introduced additional asbestos into the living spaces of the house?

e. What are the types and concentrations of asbestos measured in the indoor air in the living spaces before and after the completion of positive-pressure blower door testing or weatherization activity?

f. Does the change in asbestos levels in the indoor air indicate that positive-pressure blower door testing or weatherization activity introduced asbestos into the house?

2. Study on asbestos exposures of weatherization workers while they perform positive-pressure blower door testing or other weatherization work in houses with vermiculite insulation:

a. What level of asbestos concentrations are weatherization workers exposed to in his or her breathing zone while positive-pressure blower door testing or other weatherization work is performed? 
b. What concentrations of asbestos personal exposures arise from different weatherization activities (e.g. blowing cellulose over vermiculite insulation, weatherizing houses with existing vermiculite insulation but avoiding areas with vermiculite insulation, etc.)?

3. Additionally, study on asbestos in the existing vermiculite insulation:

a. What types and concentrations of asbestos are found in the vermiculite insulation samples taken in the house?

b. How consistent are the concentrations of asbestos measured among the samples from a given area (e.g., attic)?

c. Did the vermiculite insulation come from the Libby mine? 


\section{STUDY DESIGN}

\subsection{OVERVIEW OF THE STUDY DESIGN}

It is envisioned that 50-100 houses will be monitored from 3-5 states and 2-3 Subgrantees per state under this study. It is also envisioned that the monitoring within a state will span about one year.

States will be selected such that the five approaches currently being used in WAP to audit and weatherize houses with existing vermiculite insulation are studied:

- Weatherizing the house as normal after testing reveals that the vermiculite insulation contains less than $1 \%$ asbestos.

- Avoiding areas of the house where vermiculite insulation is installed and weatherizing the remaining areas of the house as normal.

- Blowing cellulose over the existing vermiculite insulation in an attic.

- Weatherizing the areas of the house where vermiculite insulation is installed using unique/alternative approaches developed specifically for that house.

- Performing positive-pressure blower door tests.

However, ORNL's study approach will focus on the following measurements (discussed in more detail in Section 4) conducted in each house by a sub-contracted accredited commercial firm qualified to perform sample collection work:

- Asbestos levels on 3-5 hard surfaces within the houses (e.g., floors, countertops) by collecting settled dust samples using wet wipes before positive-pressure blower door testing or weatherization work is performed to establish baseline asbestos levels and types (from here on referred to as 'wipe sampling').

- Indoor air samples collected from 3-5 locations in the living space of the house before positivepressure blower door testing or weatherization work is performed using stationary air monitors in order to establish baseline indoor air asbestos concentrations (from here on referred to as 'area sampling').

- Asbestos concentrations from 3-5 bulk samples of the vermiculite insulation found in the house to determine if the vermiculite insulation contains asbestos and originated from the Libby mine (from here on referred to as 'bulk sampling').

- Personal air samples collected from the breathing zone of at least $25 \%$ of the weatherization workers using a monitor attached to the body of the worker during the execution of positivepressure blower door testing or weatherization activities to determine the airborne asbestos levels a worker is exposed to during these activities (from here on referred to as 'personal sampling').

- Wipe sampling after positive-pressure blower door testing or weatherization work is performed from the same surfaces previously sampled.

- Area sampling after positive-pressure blower door testing or weatherization work is performed from the same locations previously sampled.

\subsection{SELECTION OF STATES}

Three to five states will be selected to participate in the study. Based on an initial review of their Weatherization Health and Safety Plans and interviews with the states, five potential states were identified for the study based on their policies and approaches to weatherizing houses with vermiculite insulation. In identifying these states, an effort was made to identify states that used a variety of the approaches to be studied. Table 2 identifies the five states along with the approaches that they use. 
Table 2. States and their approaches to weatherizing houses with vermiculite insulation.

\begin{tabular}{|c|c|c|c|c|c|}
\hline Approaches & Wisconsin & Vermont & Illinois & $\begin{array}{c}\text { North } \\
\text { Dakota }\end{array}$ & Ohio \\
\hline \multicolumn{6}{|l|}{ Weatherization: } \\
\hline $\begin{array}{l}\text { Weatherize as normal if testing indicates } \\
\text { that the vermiculite insulation contains }<1 \% \\
\text { asbestos }\end{array}$ & & & & & $x$ \\
\hline $\begin{array}{l}\text { Avoid areas of the house with vermiculite } \\
\text { insulation but weatherize the rest of the } \\
\text { house as normal }\end{array}$ & & & $\mathrm{x}$ & & $x$ \\
\hline $\begin{array}{l}\text { Blow cellulose or other insulation over the } \\
\text { existing vermiculite insulation in an attic }\end{array}$ & $x$ & & & $x$ & \\
\hline $\begin{array}{l}\text { Weatherize the areas of the house with } \\
\text { vermiculite insulation using } \\
\text { unique/alternative approaches }\end{array}$ & & $x$ & & & \\
\hline \multicolumn{6}{|l|}{ Blower Door Test: } \\
\hline Positive-pressure blower door test & $x$ & & $x$ & & $x$ \\
\hline Negative-pressure blower door test & & & & $x$ & \\
\hline No blower door test & & $x$ & & & \\
\hline
\end{tabular}

\subsection{SELECTION OF SUBGRANTEES}

Two to three weatherization agencies (referred interchangeably as Subgrantees from hereon) will be selected from each state based on the number of houses that the Subgrantee typically weatherizes in a year that have vermiculite insulation present, the approaches that they use in such houses, the Subgrantee's capacity to implement the study (e.g., time to coordinate with the house occupants, flexibility in scheduling houses for testing and weatherization, asbestos training and credentials), and recommendations from state staff. Subcontracts will be established with the chosen Subgrantee to compensate them for their time in implementing the study.

\subsection{SELECTION OF HOUSES}

Data will be collected from 50-100 houses over the course of the study. These houses will be drawn from the Subgrantee's population of houses on a rolling-basis (i.e., houses with vermiculite insulation will be brought into the study as they are encountered by the Subgrantees on a chronological order). The number of houses that will be monitored was estimated as follows:

- To evaluate the impact of weatherization activities alone without considering the impact of positive-pressure blower door testing, it was assumed that five houses could be monitored from each of the two to three Subgrantees from each of five states $(5 \times 2 \times 5=50$ in the case of two Subgrantees per state and $5 \times 3 \times 5=75$ in case of three Subgrantees per state).

- For evaluating the impact solely due to positive-pressure blower door testing, it was assumed that five houses could be monitored from each of two agencies from three of the same five states $(5 \mathrm{x}$ $2 \times 3=30$ ). Note that these houses could be a subset of the same $50-75$ houses monitored above or different than those 50-75 houses, making the total number of houses being monitored equal to roughly 100. Although Table 2 indicates that North Dakota currently allows negative-pressure blower door tests, this approach will not be monitored in this study. 
Houses included in the study will be limited to those with the following characteristics:

- Occupants must be eligible for the WAP administered in their state.

- The houses must be single-family residential buildings or side-by-side duplexes but not manufactured houses or multifamily buildings (it is assumed that the use of vermiculite insulation in manufactured houses and multifamily buildings is rare or non-existent).

\subsection{SELECTION OF ASBESTOS SAMPLING FIRMS}

An accredited commercial firm qualified to perform sample collection work (e.g., environmental consultant, a research organization, or some other type of firm legally authorized and accredited to perform asbestos-work per federal, state, and local jurisdictions) local to each state or region will be chosen and subcontracted with to collect data for this study (from here on referred to as 'asbestos sampling firm'). The asbestos sampling firm will be trained on the sampling protocol per our research needs. The asbestos sampling firm will also be responsible for following proper health and safety standards. The accreditation requirements for the asbestos sampling firm will be set in accordance with the EPA Asbestos Model Accreditation Plan (MAP) issued under the Asbestos Hazard Emergency Response Act of 1986 (AHERA) [12]. Section 7 describes in detail the applicable regulations and necessary trainings for the asbestos sampling firms to be able to collect samples for this study. All sampling personnel from the asbestos sampling firm must meet the following requirements:

- trained as an 'Asbestos Project Monitor' per MAP from an EPA Model Accreditation Course,

- trained in National Institute for Occupational Safety and Health (NIOSH) 582 course $^{4}$ for Air Sampling and Analytical Techniques (or equivalent),

- should have on-the-job training under the supervision of an experienced air monitor, and an experience of performing at least 25 final clearance air sampling,

- maintaining an active certification as a Certified Industrial Hygienist (CIH), or have experience working under a supervisor with an active $\mathrm{CIH}$ certification through the American Board of Industrial Hygiene $(\mathrm{ABIH})^{5}$.

The asbestos sampling firm will be primarily be subcontracted solely for the sample collection activity. In case of a need to perform asbestos cleanup of the house, the Subgrantee will be asked to hire another local asbestos-accredited contractor to perform a cleanup (asbestos decontamination) of the living spaces. This contractor will be an independent entity from the original asbestos sampling firm (see Section 6 for details).

\footnotetext{
${ }^{4}$ The student manual titled 'Sampling and Evaluating Airborne Asbestos Dust (582)' published by NIOSH, available at: https://ntrl.ntis.gov/NTRL/dashboard/searchResults/titleDetail/PB85246023.xhtml

${ }^{5} \mathrm{~A}$ Certified Industrial Hygienist $(\mathrm{CIH})$ is an individual who has met the minimum requirements for education and experience, and through examination, has demonstrated a minimum level of knowledge and skills in the core subject areas of the profession (http://www.abih.org/about-abih/cih-caih).
} 


\section{DATA PARAMETERS AND INSTRUMENTATION}

The data to be collected for this study can be categorized into three types:

1. Instrumentation data: These are the data on asbestos concentrations and fiber identification based on instrumentation and techniques used to collect bulk, airborne, and surface-settled asbestos. These types of data can be further categorized as:

- Vermiculite insulation material bulk sampling data

- Area sampling airborne asbestos concentration data

- Personal sampling time-weighted average airborne asbestos concentration data

- Wipe sampling data of asbestos per unit area in settled dust using wet wiping of hard surfaces

The instrumentation data will be the core piece of this study and will be the basis of any quantitative analysis. The subsections of Section 4 describe the various instruments and methods that will be used and data that will be generated in greater detail.

2. House data: A walkthrough inspection of the house will be conducted by the Subgrantee as part of the pre-weatherization data collection phase to collect descriptive information on key house characteristics. Sampling-related data will also be collected as part of the pre-weatherization testing by the asbestos sampling firm. Details of the data collected before weatherization work is performed are provided in Appendix A.

Following weatherization, the Subgrantee will provide information on vermiculite observations made while the house was weatherized and information on the weatherization work performed in the house, including the results of any blower door testing performed. Details of this data collection are provided in Appendix B.

These data will be useful for both initial exploratory data analysis as well as descriptive and inferential statistical analyses to categorize the study findings by various qualitative house characteristics, correlate the findings with any quantifiable house characteristics, and find justifications for any anomalies in the results or findings.

3. Indirect data: These are the data related to the location of the house and/or local weather-related variables that will be gathered indirectly from publicly available online repositories (e.g., from the National Oceanic and Atmospheric Administration (NOAA), the United States Geological Survey (USGS), and the US EPA). Indirect data will assist in exploring further correlations and justify results and correlations among various relevant parameters analyzed in the study. Indirect data will be accessed by ORNL.

\subsection{BULK SAMPLING}

Bulk samples of vermiculite insulation will be collected (typically from the house attic) for the positive identification and specification of asbestos fibers. Samples will be taken from 3-5 separate locations in the attic. Sampling locations will be chosen such that they are at least 10 feet apart from each other and include at least one location close to the exterior edge of attic floor (peripheral zone) and one location towards the center of the attic floor (central zone). If practically possible, the attic floor will be divided into four homogenous quadrants (for rectangular attic floors), with one sample gathered from each quadrant and with at least one sample being collected from each of the central and peripheral zones of the 
attic. Randomized approach for sampling will be used where applicable, such as the grid-partitioning method as defined in AHERA.

While the EPA's Asbestos Hazard Emergency Response Act (AHERA)[13] requires specific bulk sampling techniques and adequate training and accreditation of the person collecting the bulk sample, collection of vermiculite from residential houses has no such accreditation requirement by the EPA. The subcontracted asbestos sampling firm will collect the bulk vermiculite insulation samples for this study.

Materials required for the bulk sampling are as follows:

- Adequate personal protective equipment (PPE)

- 1-gallon re-sealable plastic bags for sample collection

- Additional re-sealable plastic bags or airtight containers to put sealed samples in for shipping

- Disposable scoop (flat tip)

- Spray bottle filled with water

- Clean damp cloths or rags (preferably stored inside a clean airtight container)

In collecting the bulk samples, adequate necessary personal protective equipment (PPE) and containment strategies using plastic sheeting will be used per OSHA and AHERA requirements for Class III asbestos work (refer to Section 7 for asbestos work classifications). Asbestos exposure is primarily an inhalation hazard. Adequate respiratory protection must be exercised by all sampling personnel when encountering presumed asbestos containing materials like vermiculite insulation. It will be emphasized to all sampling personnel to minimize their direct physical contact with or any physical disturbance to vermiculite or any other presumed asbestos containing material encountered in the house. Bulk sampling will be performed wearing NIOSH certified respirators in accord with OSHA Standards (29 CFR 1910.1001 [2] and 1910.134 [14]) and PPEs including a minimum of:

- NIOSH P100 rated half-face respirator [15]

- Disposable hooded coveralls

- Safety goggles

- Hard hat

- Inner and outer chemical-resistant gloves

- Disposable, outer chemical-resistant boot covers

It will also be required for the sampling firm to ensure an illumination of a minimum of 5 Foot-Candles per the 29 CFR 1910.120 OSHA Standard [16].

Nitrile gloves will be used while handling all sample bags and accessories both before and after sampling. To collect a sample, a $1 \mathrm{~m} \times 1 \mathrm{~m}$ area of bulk vermiculite material will first be wetted with a spray of amended water (water to which surfactant chemicals have been added to reduce the surface tension) so that the tendency of the presumed friable asbestos attached to the vermiculite to get airborne is suppressed, thus reducing a respiratory hazard to the person collecting the bulk sample. The EPA describes the composition of amended water used for asbestos wetting in its "Guidance for Controlling Asbestos-Containing Materials in Buildings", EPA 560/5-85-024 (Purple Book)[17]. It recommends the use of a 50:50 mixture of polyoxyethylene ester and polyoxyethylene ether, or the equivalent, in a 0.16 percent solution (1 ounce to 5 gallons) of water.

A one-gallon resealable plastic bag will be filled with vermiculite insulation from the sampled area. A metal scoop (approximately $12 \mathrm{~cm} \times 8 \mathrm{~cm}$ with a flat edge) will be used to take scoops of the vermiculite insulation, making sure to collect the vermiculite insulation from the bottom-most part of the attic floor. This procedure is intended to ensure that any heavy materials, such as fibrous amphiboles that may have settled in the vermiculite insulation, will be sampled. Multiple scoops will be taken as necessary to fill the one-gallon plastic bag. Scoops must be cleaned between each scoop collection, including changing out 
gloves between each collection to prevent cross contamination. The outside of the plastic bag will be cleaned with a damp cloth. The bag will then be placed in another clean, re-sealable plastic bag or rigid airtight metal or plastic container and prepared for shipment. The 3-5 separate plastic bags of bulk samples will be labelled as per the sample naming convention in Appendix $\mathrm{C}$ and will be shipped to the analytical laboratory chosen for this study according to the protocols described in Section 4.6.

It is to be noted that a negative bulk sampling result does not establish that there is no asbestos hazard present but that the locations that were tested were not contaminated. As this does not eliminate the possibility that asbestos is present, all vermiculite will be treated as if it is contaminated

\subsection{AREA SAMPLING}

Area sampling will be performed in 3 to 5 locations in the living spaces of the house both before and after the positive-pressure blower door testing or weatherization work activities. The area sampling will be conducted in a living room, bedroom(s), kitchen, dining room, and/or hallway(s) according to the judgement of the sampling personnel as to whichever locations best represent the layout of the house, occupant convenience, and area usage patterns.

Two area samples will be collected side-by-side in each location, one following the EPA AHERA (40 CFR Appendix A to Subpart E of Part 763) and the other following the NIOSH 7400 sampling methods. The NIOSH 7400 sampling method will enable an on-site analysis of the collected area sample using phase contrast microscopy (PCM). This capability will allow for the identification of any immediately urgent issue related to elevated asbestos levels caused by any intervention activity (like weatherizationrelated) in the house. The EPA AHERA sampling method will enable a transmission electron microscopy (TEM) analysis on the collected area samples which can confirm the presence of asbestos, if any, and also identify the asbestos types and quantify their concentrations in the collected samples.

An area sampling kit will be used for each type of area sampling (EPA AHERA and NIOSH 7400) consisting of an air sampling vacuum pump drawing air through an air sampling cassette.

The necessary apparatus for area sampling consists of:

- Vacuum pump (Gilian AirCon-2 Area Sampling Pump or equivalent)

- Flexible tubing

- Tripod mast

- Sampling cassette $(0.45 \mu \mathrm{m}$ TEM Cassette GCS25455-506 or equivalent for EPA AHERA sampling method and $0.8 \mu \mathrm{m}$ Zefon $25 \mathrm{~mm}$ Z008GGA Cassette ${ }^{7}$ or equivalent for NIOSH 7400 sampling method)

- Pump flow calibrator (GoCal Air Flow Calibrator ${ }^{8}$ or equivalent)

Air drawn through the pump will be collected through a tube whose other end will be fitted with a sampling cassette fitted with a $25 \mathrm{~mm}$ diameter $(0.45 \mu \mathrm{m}$ maximum pore size for EPA AHERA method and $0.8 \mu \mathrm{m}$ for NIOSH 7400 method) mixed cellulose ester membrane filter and an electrically conductive $50 \mathrm{~mm}$ extension cowl. An electrically conductive cassette with a conductive cowl is necessary to prevent loss of fibers to the walls of the cassette due to electrostatic forces.

For each area sampling apparatus, the area sampling cassette will be positioned four to six feet above floor level, angled down at approximately $45^{\circ}$ to avoid collection of passive deposition, and connected to the pump with a flexible tube. The inlet of the cassette will be elevated above the ground using a tripod mount. The air sample will be collected using a high-flow air sampling vacuum pump running at 9.9 liters

\footnotetext{
${ }^{6}$ https://www.sensidyne.com/air-sampling-equipment/sampling-media-accessories/membrane-filters-andcassettes.php

${ }^{7}$ https://www.zefon.com/cassette-25mm-3pc-08m-mce-green-grid-50bx

${ }^{8} \underline{\mathrm{https}: / / w w w . s e n s i d y n e . c o m / a i r-s a m p l i n g-e q u i p m e n t / c a l i b r a t i o n-e q u i p m e n t / s e n s i d y n e-g o-c a l-a i r-f l o w-c a l i b r a t o r / ~}$
} 
per minute (lpm) to ensure the fastest allowable sampling period (EPA AHERA sampling method precludes the use of higher than $10 \mathrm{lpm}$ sampling flow rate for area sampling pumps). Each area sampling pump will be calibrated to operate at $9.9 \mathrm{lpm}$ before each use with a secondary calibration device like an on-device rotameter, which in turn, is calibrated using a NIST ${ }^{9}$-traceable primary air flow calibration device (GoCal Air Flow Calibrator or equivalent) before each field deployment of the instrument. Flow rate measurements of the sampling pumps will be made both at the beginning and end of the sampling period, using the calibrated flow meter. The mean values of these two measurements will be used to calculate the total air volumes sampled by each pump. If the difference in the flow rates at the beginning and end of the sampling period is greater than $10 \%$, the corresponding sample will be labelled as suspect or void due to sampling errors.

Area sampling will be done for at least 305 minutes ( 5 hours and 5 minutes) to ensure that a minimum of 3000 liters of air volume is sampled. PCM analysis of the samples collected with the NIOSH 7400 method will be performed on-site with a portable microscope following the NIOSH 7400 PCM analysis method.The sample filter cassettes along with field blank cassettes (see Section 4.5) will be sealed in an airtight container or plastic bag with additional exterior labelling and shipped to a pre-identified accredited analytical laboratory (see Section 4.6) to be analyzed using the EPA AHERA TEM method.

\subsection{PERSONAL SAMPLING}

Personal samples will be collected from the breathing zone of at least $25 \%$ of the workforce from the Subgrantee involved in weatherization activities per house (in accordance with OSHA worker exposure monitoring requirements - 29 CFR 1926.1101 [18]). The workers performing the major portion of the weatherization activities in or near the areas identified to have vermiculite insulation will be selected for personal sampling. Personal sampling procedures developed here are in accordance with Appendix A of the OSHA Asbestos Standard 29 CFR 1910.1001 [19] for active air sampling using a portable pump attached to each of the weatherization workers, drawing air through a sampling cassette.

The necessary equipment for personal sampling includes:

- Sampling cassette (Zefon Z008BA Cassette or equivalent ${ }^{10}$, suitable for analysis using NIOSH Methods 7400 and 7402)

- Battery-powered personal air sampling pump (Gilian BDX $\mathrm{II}^{11}$ or equivalent)

- Pump flow calibrator (same as area sampling)

- Flexible tubing and associated accessories

The personal air sampling will be conducted by attaching a portable air sampling pump to the worker's waist outside the protective suit (if used). A flexible sampling tube will run from the sampling pump, over the worker's shoulder, and to the worker's lapel where a personal sampling cassette will be attached. The tubing will be taped to the worker's external apparel where necessary. The sampling cassette will be identical to the area sampling cassette but suitable for both NIOSH 7400 and 7402 analysis methods $(0.8$ $\mu \mathrm{m}$ pore size, $25 \mathrm{~mm}$ diameter MCE filter cassette). The personal samples will be first analyzed on-site using the NIOSH 7400 method which uses the PCM technique before further analysis of the same sample using NIOSH 7402 method in an analytical laboratory, which uses the TEM technique for analysis (See Section 5 for details on the analytical methods and techniques).

\footnotetext{
${ }^{9}$ NIST $=$ National Institute of Standards and Technology

${ }^{10}$ https://industrialsafety.com/zefon-z008ba-cassette-25mm-3-pc-0-8um-mce-asbestos-pcm-box-of-50-zefonz008ba.html?gclid=CjwKCAiA3uDwBRBFEiwA1VsajOpqJhVDbNUhxkaDJuYWmlP E 1qiV78AROCZ56vwU9 mHuJ0gz8ZxhoClWEQAvD BwE

${ }^{11}$ https://www.sensidyne.com/air-sampling-equipment/gilian-air-sampling-pumps/bdx-ii-air-sampling-pump/
} 
Personal sampling will be conducted in one of the two possible ways:

1. If the weatherization activity is anticipated to last for less than 8 hours, 30-minute sampling will be done during the dustiest job performed by the weatherization worker. This measurement can be compared against the OSHA excursion level (EL) of $1 \mathrm{f} / \mathrm{cc}$ for a 30-minute time-weighted average (TWA) concentration, as determined by the NIOSH 7400 method of sample analysis. It can be noted that personal sampling during positive-pressure blower door testing can only be of this type due to the short duration required for the test ( $\sim 30$ minutes to 1 hour).

2. If weatherization activities will be performed for eight hours or more at a stretch, an 8-hour personal sampling will also be performed that can be compared against the OSHA permissible exposure limit (PEL) of $0.1 \mathrm{f} / \mathrm{cc}$ for an 8-hour TWA concentration, as determined by the NIOSH 7400 method of sample analysis.

For personal sampling in extremely dusty environments (e.g., spraying cellulose over vermiculite insulation in the attic), proper care will be taken to prevent rapid clogging of the personal sampling cassettes. To prevent this, two measures will be taken:

1. Sampling at the lowest possible pump flow rate: Personal sampling will be done with a sampling pump pre-calibrated to $2.0 \mathrm{lpm}$ flow rate, per OSHA regulations [19].

2. Sequential sampling: The technique of sequential sampling will also be used for personal sampling in extrememely dusty environments. Sequential sampling includes changing cassettes every 5 to 10 minutes during the 30-minute sampling period when very dusty weatherization activities are performed. In the unlikely event that longer ( 8 hours or more) weatherization activities are performed which are also extremely dusty in nature, (e.g., blowing loose fill insulation into the walls), sequential sampling can be performed by changing the personal sampling cassettes less frequently (e.g., every hour or every two hours). The need and frequency of changing filter cassettes will be assessed on a case-by-case basis depending on the nature of the weatherization activities being performed, the duration of time needed by the activities, and the amount of dust generated by those activities.

After performing PCM analysis on a small sector of a collected personal sampling cassette's filter media, the remaining cassette filter media will be used for TEM analysis using NIOSH 7402 Method. First, the cassette with the remaining filter media will be appropriately labelled per the labelling protocol in Appendix C, sealed in an airtight container or plastic bag with additional exterior labelling, and will be shipped to a pre-identified accredited analytical laboratory (see Section 4.6) where the cassette filter will be analyzed using the NIOSH 7402 TEM method. Field blank cassettes will be provided to the analytical laboratory along with the collected samples as required by the analytical method (see Section 4.5).

\subsection{SURFACE WIPE SAMPLING FOR SETTLED ASBESTOS}

Wipe sampling (using wet wipes) will be performed to collect settled asbestos on three to five locations in the house (e.g., smooth, hard surfaces like floor tiles, countertops, tables). The purpose of wipe sampling will be to (a) establish a baseline in each house of the concentration per unit area of asbestos fibers found in settled dust, (b) to investigate the composition (type) of asbestos found in the settled dust so that it can be correlated with the type of asbestos found in vermiculite insulation as contaminant (e.g., tremoliteactinolite, if tested positive in vermiculite insulation bulk sample), and (c) to compare the pre- and postasbestos types after the positive-pressure blower door test and weatherization work activities.

Some previous studies have also incorporated micro-vacuum sampling for settled asbestos in fabric and carpet surfaces [20]-[22] using a similar sampling apparatus to a personal air monitoring pump-cassette array. However, evaluation studies comparing the wipe sampling technique to the micro-vacuum 
sampling technique have concluded that wipe sampling techniques have equivalent or better capture efficiency for settled asbestos on smooth surfaces [23], [24]. For the sake of simplicity in our analysis, we will only use the wet wipe sampling technique as no significant new information is expected from an additional effort made to collect micro-vacuum samples, compared to the (wet) wipe samples.

Wipe samples will be taken according to the ASTM D6480-19 Standard (see Section 5). The preweatherization activity wipe sampling will be performed with a template-assisted sample collection procedure in which a rectangular template with a fixed opening area is used on the surface being wipesampled. After the weatherization activities are performed, the post-weatherization activity wipe sampling will be performed which will eventually enable a direct qualitative and quantitative analysis of the wipe samples collected before and after the weatherization process. Detailed procedures for wipe sampling are provided in Appendix D. The samples will be packed in a fiber-free material to minimize the potential for sample contamination. Properly labelled samples will be shipped to an analytical laboratory (see Section 4.6) along with field blank wipes (see Section 4.5), separately packed from any bulk or air samples.

\subsection{BLANKS}

A certain number of blanks may be required by the analytical laboratory for each set of samples that need to be analyzed. The exact number of blanks required will depend on the analytical test being performed on the samples. Two different types of blanks may be required by the analytical laboratory: field blanks and media blanks.

Field blanks are unused samplers that taken to the sampling site just like a regular sampler, handled exactly like the actual sampler, kept together with the actual sampler so that it gets exposed to environmental conditions almost exactly similar to the actual sampler, but the actual sampling activity (like drawing air through it in the case of an area sampling cassette) is not performed using the field blank sampler. Media blanks are simply unopened, new samplers which are sent with the samples (but these blanksa are not usually taken to the field) to enable the detection of any pre-existing contaminantion in an unopened sampler.

Field blanks are essential to quantify the inadvertent contamination of any kind of sample during sample handling, storage, and transportation to the analytical laboratory. In the absence of field blanks, sample analysis could report values higher than what they actually were in the field. Any quantity of asbestos detected as contamination in the field blank will be attributed to the handling, storage, or transportation of the samples, and will be deducted from the sample results to represent the actual values measured during sampling event.

An adequate number of field and media blanks of all area samples, personal samples, and surface wipe samples will be provided with each sample batch shipped to the analytical laboratory per the laboratory guidance. For wipe sampling, a field wipe blank is a clean, unused, moistened wipe from the same supply that is used for sampling. Field wipe blanks will be processed in the same manner used to collect field samples with the exception that no surface is wiped. Each wipe designated as a field blank will be removed from the bulk pack, moistened, and folded in the same manner as the field samples and placed in a sample container labeled as a field blank. Wipe samples will be accompanied with one field blank per batch of 3 to 5 samples, as required by the ASTM D6480-19 Standard (see Section 5).

For area samples being analyzed with TEM, each batch of 3 to 5 cassettes (one batch for preweatherization and one batch for post-weatherization) will be accompanied by 3 field blanks per batch (following EPA AHERA standard). For on-site evaluation with PCM of a batch of 3 to 5 area samples using NIOSH 7400 method, 3 field blanks per batch will be evaluated as well. Each batch of 1 to 5 personal sampling cassettes will include 2 field blanks (following OSHA asbestos standard). 
All blanks will be handled together with the samples following daily activities (being handled under the same environmental conditions and handling processes).

\subsection{SAMPLE SHIPMENT}

Chain of Custody (COC) forms will be filled out properly per the analytical laboratory directions. The samples will be shipped out to the respective laboratory along with the COC forms and other necessary documentation using registered mail service via ground transportation (U.S. Department of Transportation regulations require the shipment of ACM to be done only via ground transportation, and not through air transportation). Care will be taken during sample shipment to minimize sample rattling or exposure to static electricity by using anti-static bubble wrap bags and by not using expanding polystyrene peanuts, paper shreds, or excelsior as packaging material. To avoid the possibility of crosscontamination, bulk samples will always be shipped in separate mailing containers as a standard practice. Frequent direct communication (at least one phone call or email correspondence per shipment) will also be made with the analytical laboratory to keep track of shipped, received, and analyzed samples along with anticipated samples that will be shipped soon in the immediate future.

\subsection{CALIBRATIONS AND QUALITY ASSURANCE OF INSTRUMENTATION DATA}

Instruments being used for the study will be calibrated per manufacturer's guidelines. Active factory calibration certificates will be maintained for each instrument, as required. Proper instrument handling will be ensured during instrument shipment per manufacturer's guidelines. Field calibrations of sampling pumps will be done using a NIST-traceable flow calibrator (like the TSI 4146 Primary Calibrator ${ }^{12}$ or equivalent) before and after each use to ensure proper flow rates per the sample analysis requirements.

If flow-meter contamination is suspected while calibrating the airflow through the sampling pumps (e.g., by coming in direct contact with vermiculite insulation or dust while handling), the flow meters will be either replaced with a new one or cleaned and recalibrated before use to avoid transfer of asbestos contamination from the flow meter to the sample being collected. Sampling pumps will be monitored on a periodic basis during the entire sampling time with the help of an on-device indication of flow rate (like a rotameter which is calibrated) and any sign of malfunction or issues that might cause error in the collected data. Caps will be placed over the open end of the cassette after sampling to prevent contamination, and cassettes will be stored and transported with the filter face-upwards to reduce the loss of filter-deposited asbestos due to vibrations or jerking and the consequent loss of fibers before laboratory analysis.

Different types of samples will not be stored together or shipped to the analytical laboratory together in order to avoid cross-contamination of samples. For example, bulk samples will be stored, handled, and shipped separately than wipe samples, and similarly with area and personal samples.

Quality assurance and quality control (QA/QC) will also be routinely done in the data obtained from the analytical laboratory. Initially the asbestos sampling firm, then the study team will perform data QA/QC. Examples include: flow rates within specified range, number of samples and blanks matching with the requirements, time length of sample collection within the specified range, flagging data outliers and establishing their causes, ensuring non-detects in media and laboratory blanks, etc.

12 https://www.tsi.com/products/aerosol-and-dust-monitors/primary-calibrators/primary-calibrator-4146/ 


\section{LABORATORY ANALYSIS OF SAMPLES}

One commercial laboratory providing analytical services for environmental samples will be identified and contracted for conducting analysis of all samples collected for this study. The selected lab will have to be compliant with the Asbestos Hazard Emergency Response Act of $1986^{13}$ (AHERA) requirements for analytical laboratories and should be accredited under the American Industrial Hygiene Association (AIHA) ${ }^{14}$ and the National Voluntary Laboratory Accreditation Program ${ }^{15}$ (NVLAP). As a minimum, the laboratory should have the capability of providing the following analytical services:

- Bulk samples:

- Polarized light microscopy (PLM) and TEM according to the method EPA/600/R-04-004 (Cincinnati Method) [25]

- Barium test for identification of the source mine using the EPA Method 6010D: Inductively Coupled Plasma - Optical Emission Spectrometry (ICP-OES) [26]

- Air samples (both area and personal): TEM analysis using the AHERA method (40 CFR Appendix A to Subpart E of Part 763) [27]

- Personal samples: Phase contrast microscopy (PCM) using NIOSH Method 7400 [28] followed by NIOSH Method 7402 (TEM) [29].

- Wipe samples: ASTM D6480-19: Standard Test Method for Wipe Sampling of Surfaces, Indirect Preparation, and Analysis for Asbestos Structure Number Surface Loading by Transmission Electron Microscopy [30]

Table 3 below enlists the analytical test methods along with relevant information applicable to this study, along with useful reference levels established by regulatory bodies. However, these reference levels will not be used with the objective to check regulatory compliance. Instead, they will serve as benchmarks for our study team to decide on critical decisions like when to assume it is safe for the homeowners and weatherization crew to be inside the house without respiratory protection, and when to require an asbestos clean-up in the event of asbestos contamination in the house due to positive-pressure blower door test or weatherization related activities.

\footnotetext{
${ }^{13}$ The Asbestos Hazard Emergency Response Act (AHERA) requires local educational agencies to inspect their school buildings for asbestos-containing building material, prepare asbestos management plans and perform asbestos response actions to prevent or reduce asbestos hazards (https://www.epa.gov/asbestos/asbestos-laws-andregulations\#ahera)

${ }^{14}$ https://www.aiha.org/

15 The National Voluntary Laboratory Accreditation Program (NVLAP) provides third-party accreditation to testing and calibration laboratories in response to legislative actions or requests from government agencies or private-sector organizations. NVLAP-accredited laboratories are assessed against the management and technical requirements published in the International Standard, ISO/IEC 17025:2017 (https://www.nist.gov/nvlap)
} 
Table 3. Analytical test methods with their descriptions applicable to this study.

\begin{tabular}{|c|c|c|c|c|c|}
\hline $\begin{array}{l}\text { Method } \\
\text { Name }\end{array}$ & $\begin{array}{l}\text { Sample } \\
\text { Type }\end{array}$ & $\begin{array}{l}\text { Analytical } \\
\text { Techniques }\end{array}$ & Process Description & $\begin{array}{l}\text { Reporting } \\
\text { Unit }\end{array}$ & $\begin{array}{l}\text { Useful } \\
\text { Reference Level }\end{array}$ \\
\hline $\begin{array}{l}\text { EPA/600/R } \\
\text {-04-004 } \\
\text { (Cincinnati } \\
\text { Method) }\end{array}$ & $\begin{array}{l}\text { Bulk } \\
\text { samples }\end{array}$ & $\begin{array}{l}\text { PLM, } \\
\text { TEM, } \\
\text { hydrostatic } \\
\text { buoyancy }\end{array}$ & $\begin{array}{l}\text { This method is suitable for } \\
\text { vermiculite insulation bulk sample } \\
\text { testing [31]. Vermiculite insulation } \\
\text { sample (1 kg) is analyzed by taking } \\
\text { advantage of the fact that larger } \\
\text { bundles of asbestos would rapidly } \\
\text { settle out (or "sink") in water leaving } \\
\text { the vermiculite floating on the } \\
\text { surface. The sample is dried, } \\
\text { weighed, placed in a beaker and } \\
\text { suspended in water. After stirring, } \\
\text { the sample is allowed to separate } \\
\text { into 'sinks', 'floats' and 'suspended' } \\
\text { fractions. The sinks and floats } \\
\text { fractions are dried, weighed and } \\
\text { analyzed by PLM. If no amphibole } \\
\text { fibers are detected, further analysis } \\
\text { of the suspended fraction by TEM is } \\
\text { recommended. This method } \\
\text { provides a procedure for the rapid } \\
\text { characterization of fibrous } \\
\text { amphibole constituents of } \\
\text { vermiculite attic insulation [32]. }\end{array}$ & $\begin{array}{l}\text { Asbestos as } \\
\text { a percentage } \\
\text { of total } \\
\text { vermiculite } \\
\text { sample } \\
\text { weight (\%) }\end{array}$ & $1 \%$ by weight ${ }^{*}$ \\
\hline $\begin{array}{l}\text { Test for } \\
\text { Barium } \\
\text { using EPA } \\
6010 \mathrm{D}\end{array}$ & $\begin{array}{l}\text { Bulk } \\
\text { samples }\end{array}$ & ICP-OES & $\begin{array}{l}\text { "Inductively coupled plasma- } \\
\text { optical emission spectrometry (ICP- } \\
\text { OES) is a } \\
\text { spectrometric technique used to } \\
\text { determine trace elements in aqueous } \\
\text { solutions. In ICP-OES, a sample } \\
\text { solution is aspirated (i.e., nebulized) } \\
\text { continuously into an inductively } \\
\text { coupled, argonplasma discharge, } \\
\text { where analytes of interest are } \\
\text { converted to excited-state, gas-phase } \\
\text { atoms or ions. As the excited-state } \\
\text { atoms or ions return to their ground } \\
\text { state, they emit energy in the form of } \\
\text { light at wavelengths that are } \\
\text { characteristic of each specific } \\
\text { element. The intensity of the energy } \\
\text { emitted at the chosen wavelength is } \\
\text { proportional to the amount } \\
\text { (concentration) of that element in the } \\
\text { analyzed sample. Thus, by } \\
\text { determining which wavelengths are } \\
\text { emitted by a sample and their } \\
\text { respective intensities, the elemental } \\
\text { composition of the given sample } \\
\text { relative to a reference standard may } \\
\text { be quantified." [26] }\end{array}$ & $\begin{array}{l}\text { Barium } \\
\text { concentratio } \\
\mathrm{n} \text { in parts } \\
\text { per million } \\
(\mathrm{ppm})\end{array}$ & $\begin{array}{l}\text { Barium } \\
\text { concentration } \\
\text { greater than } \\
1500 \text { ppm can } \\
\text { uniquely } \\
\text { identify the } \\
\text { source of } \\
\text { vermiculite as } \\
\text { the Libby Mine } \\
\text { in Montana } \\
\text { [33]. This is not } \\
\text { a regulatory } \\
\text { threshold but is } \\
\text { used by the } \\
\text { Zonolite Attic } \\
\text { Insulation Trust } \\
\text { Fund [11] as the } \\
\text { test method to } \\
\text { positively } \\
\text { identify a } \\
\text { vermiculite } \\
\text { sample } \\
\text { originating } \\
\text { from the Libby } \\
\text { mine. }\end{array}$ \\
\hline NIOSH & Air & PCM & This is one of the cheapest and most & Fibers per & OSHA EL: 1 \\
\hline
\end{tabular}




\begin{tabular}{|c|c|c|c|c|c|}
\hline 7400 & $\begin{array}{l}\text { (Personal } \\
\text { and Area } \\
\text { samples) }\end{array}$ & & $\begin{array}{l}\text { popular test methods in the asbestos } \\
\text { industry that provides estimates of } \\
\text { total fiber counts collected through } \\
\text { air sampling on the sampling } \\
\text { cassette filter. Point counting is } \\
\text { often done on-site using an } \\
\text { automated PCM microscope. This } \\
\text { method, however, cannot positively } \\
\text { identify asbestos fibers and gives a } \\
\text { total count of physical structures } \\
\text { identified as "fibers" (length-to- } \\
\text { width ratio of }>3: 1 \text { and length }>5 \\
\mu \mathrm{m}) \text {. }\end{array}$ & $\begin{array}{l}\text { cubic } \\
\text { centimeters } \\
(\mathrm{f} / \mathrm{cc})\end{array}$ & $\begin{array}{l}\text { f/cc for personal } \\
\text { samples taken } \\
\text { for } 30 \text {-minutes } \\
\text { of work; } \\
\text { OSHA PEL: } 0.1 \\
\text { f/cc for personal } \\
\text { samples taken } \\
\text { for } 8 \text { or more } \\
\text { hours of work; } \\
\text { EPA AHERA } \\
\text { clearance level: } \\
0.01 \text { f/cc for } \\
\text { area samples } \\
\text { when } \\
\text { vermiculite } \\
\text { disturbed is less } \\
\text { than } 160 \text { linear } \\
\text { ft. or } 260 \text { square } \\
\text { feett. }\end{array}$ \\
\hline $\begin{array}{l}\text { NIOSH } \\
7402\end{array}$ & $\begin{array}{l}\text { Air } \\
\text { (Personal } \\
\text { samples) }\end{array}$ & TEM & $\begin{array}{l}\text { This is a companion method to the } \\
\text { NIOSH } 7400 \text { method often used to } \\
\text { analyze personal breathing zone air } \\
\text { samples, and uses TEM usually on } \\
\text { the same sampling filter media after } \\
\text { the PCM analysis using the NIOSH } \\
7400 \text { method has been performed, } \\
\text { and when microscopical results } \\
\text { warrant a direct comparison to TEM } \\
\text { results. As in PCM method, fibers } \\
>5 \mu \mathrm{m} \text { long and }>0.25 \mu \mathrm{m} \text { in } \\
\text { diameter are counted and this } \\
\text { method requires a minimum } \\
\text { sampling volume of } 400 \text { liters. }\end{array}$ & $\begin{array}{l}\text { Structures } \\
/ \mathrm{mm}^{2} \text { filter } \\
\text { area }\left(\mathrm{s} / \mathrm{mm}^{2}\right)\end{array}$ & None \\
\hline $\begin{array}{l}\text { EPA } \\
\text { AHERA } \\
\text { (40 CFR } \\
\S 763 \text { App. } \\
\text { A Subpart } \\
\text { E) }\end{array}$ & $\begin{array}{l}\text { Air (Area } \\
\text { samples) }\end{array}$ & TEM & $\begin{array}{l}\text { This is the first fully reviewed and } \\
\text { promulgated TEM protocol in the } \\
\text { U.S. Asbestos abatement carried out } \\
\text { in public schools in the U.S. are } \\
\text { subject to regulations under the } \\
\text { AHERA act which includes detailed } \\
\text { procedures for sampling and analysis } \\
\text { of samples to investigate the } \\
\text { presence and concentration of } \\
\text { asbestos for the clearance testing } \\
\text { before the abated areas can be re- } \\
\text { occupied. }\end{array}$ & $\begin{array}{l}\text { Structures } \\
\text { per square } \\
\text { millimeters } \\
\left(\mathrm{s} / \mathrm{mm}^{2}\right) \text { of } \\
\text { sampling } \\
\text { filter area, } \\
\text { and } \\
\text { structures } \\
\text { per cubic } \\
\text { centimeters } \\
\left(\mathrm{s} / \mathrm{cm}^{3}\right) \text { of } \\
\text { air volume } \\
\text { sampled }\end{array}$ & $\begin{array}{l}\text { EPA AHERA } \\
\text { clearance level: } \\
70 \mathrm{~s} / \mathrm{mm}^{2} \text { when } \\
\text { vermiculite } \\
\text { disturbed is } \\
\text { more than } 160 \\
\text { linear ft. or } 260 \\
\text { square feet". }\end{array}$ \\
\hline $\begin{array}{l}\text { ASTM } \\
\text { D6480 [34] }\end{array}$ & $\begin{array}{l}\text { Settled } \\
\text { Dust } \\
\text { (Wipe } \\
\text { samples) }\end{array}$ & TEM & $\begin{array}{l}\text { This is a popular standard for the } \\
\text { identification (including types) and } \\
\text { quantification of asbestos in settled } \\
\text { dust using wet wiping of smooth } \\
\text { hard surfaces (of known area) } \\
\text { followed by an indirect sample } \\
\text { preparation technique of transferring } \\
\text { the wipe material to an aqueous } \\
\text { suspension of known volume, } \\
\text { filtering the aliquots through a }\end{array}$ & $\begin{array}{l}\text { Structures } \\
\text { per square } \\
\text { centimeters } \\
\text { of surface } \\
\text { area wiped } \\
\left(\mathrm{s} / \mathrm{cm}^{2}\right)\end{array}$ & $\begin{array}{l}10,000 \mathrm{~s} / \mathrm{cm}^{2} \\
\text { detected } \\
\text { asbestos to be } \\
\text { taken as a } \\
\text { demarcation } \\
\text { between } \\
\text { "clean" and } \\
\text { "contaminated" } \\
\text { surfaces, based } \\
\text { on an earlier }\end{array}$ \\
\hline
\end{tabular}




\begin{tabular}{|l|l|l|l|l|}
\hline & \multicolumn{1}{|l|}{$\begin{array}{l}\text { membrane filter, and the final } \\
\text { analysis of the membrane filter } \\
\text { being performed using TEM, } \\
\text { electron diffraction and energy } \\
\text { dispersive X-ray analysis at a } \\
\text { magnification of 15,000 to 20,000×. }\end{array}$} & $\begin{array}{l}\text { study from } \\
\text { Montana Tech }\end{array}$ \\
\hline$\underline{\text { Notes: }}$ \\
Regulatory threshold commonly used in most states \\
${ }^{\dagger}$ Montana Asbestos-Safe Weatherization Demonstration Project [35] \\
${ }^{\ddagger}$ In accordance with EPA AHERA standards.
\end{tabular}




\section{WORKFLOW}

As houses with vermiculite insulation are identified by the Subgrantees and the occupant's consent to participate in the study is obtained, a scheduling chart will be maintained for conducting the sampling and weatherization work in the study houses collectively by the ORNL study team and the Subgrantee (the term 'weatherization work' from here on will mean either just the positive-pressure blower door test alone, weatherization activities alone, or a combination of the two).

In a single house, a typical sequence of activities to be carried out for the sampling effort is outlined as follows:

1. Initial contact to obtain the occupant's consent to participate in the study.

2. Relocate the households (e.g., to a local motel)

3. Schedule the pre-weatherization sampling visit, the weatherization work sampling visit(s), and the post-weatherization work sampling visit.

4. Pre-weatherization work sampling visit:

a. House walkthrough survey

b. Pre-weatherization sampling day preparations (the occupants will be asked to keep all windows closed, not engage in any major dust producing activities including vacuuming, and not to move any furniture for at least 24 hours prior to testing)

c. Wipe sampling

d. Area sampling (three to five locations)

5. Weatherization work sampling visit(s):

a. Bulk vermiculite insulation sample collection before or after executing weatherization work

b. Personal sampling on weatherization workers

6. Post-weatherization work sampling visit:

a. Post-weatherization activity surveys

b. Wipe sampling (same areas as before)

c. Area sampling (three to five locations, same locations as before)

It is anticipated that these measurements will be made on multiple days because of the length of time needed to make the indoor air samples ( $\sim 5$ hours), the time required to perform the weatherization activities in the house, and other logistical considerations. For example, when positive-pressure blower door tests or installing cellulose over the existing vermiculite insulation is being studied, preweatherization data may be able to be collected on the first day and the results will be analyzed by an analytical laboratory. Weatherization-related work, will be performed in the next step, only after the laboratory results of TEM analysis have been received from the pre-weatherization step. Postweatherization data collection will be collected immediately following the completion of the weatherization work. For the other three approaches being studied, there will likely be at least several days between when the pre- and post-weatherization measurements are made because of the length of time needed to complete the house weatherization activity.

Each household will receive a $\$ 50$ gift card as an incentive for participating in the study. Each participating house will also be given an informative packet of asbestos risks in houses with existing vermiculite insulation and measurement readings will be shared with the homeowner. 
Figure 1 below depicts the workflow of the overall study activities in the form of a flowchart. Before any positive-pressure blower door testing or weatherization activity is preformed in a house, the households will be temporarily relocated from their house (e.g., to a local motel). Then, the initial area sampling will be analyzed to determine if there is a high (or unsafe) level of airborne asbestos fibers pre-existing in the house. If a PCM analysis indicates greater than $0.01 \mathrm{f} / \mathrm{cc}$, the Subgrantee will be immediately notified of the high asbestos levels. The Subgrantee will be required to take adequate protection including the use of adequate PPEs before commencing work, and throughout their presence in the house.

Upon completion of a positive-pressure blower door test or weatherization work, an on-site PCM analysis of the post-blower door test area samples will be performed using NIOSH 7400 method, followed by the EPA AHERA method TEM analysis in the analytical laboratory. If no weatherization work will be done in the house following the positive-pressure blower door test, the post-blower door test TEM result will be treated as the 'clearance test' result. If, in any one of the 3-5 area samples taken after weatherization show a concentration higher than $70 \mathrm{~s} / \mathrm{mm}^{2}$, study funds will be used to hire another local asbestos contractor (independent from the asbestos sampling firm) to decontaminate the living space until AHERA clearance tests are negative (i.e., TEM results are $<70 \mathrm{~s} / \mathrm{mm}^{2}$ ). The decontamination will be performed on a case-by-case basis. The exact steps taken for each house decontamination will be the responsibility of the hired asbestos contractor and is anticipated to depend on the characteristics of the house and the concentration of the asbestos in the indoor air. Another clearance test will be performed by the original asbestos sampling firm and the process of asbestos decontamination of the living spaces followed by another clearance test will be repeated until the clearance test finally shows that the house is safe for reoccupancy (PCM test result $<0.01 \mathrm{f} / \mathrm{cc}$ or TEM test result $<70 \mathrm{~s} / \mathrm{mm}^{2}$ ). This final determination regarding safety of the house for reoccupancy will be made by the legal authority of the accredited asbestos sampling firm hired for the sample collection for this study.

If the house will be receiving both a positive-pressure blower door test and weatherization work, PCM and TEM analysis will be performed as outlined above after the blower door test but before the weatherization work is started and again after the weatherization work is performed. Actions will be taken based on the PCM and TEM results as outlined above. 


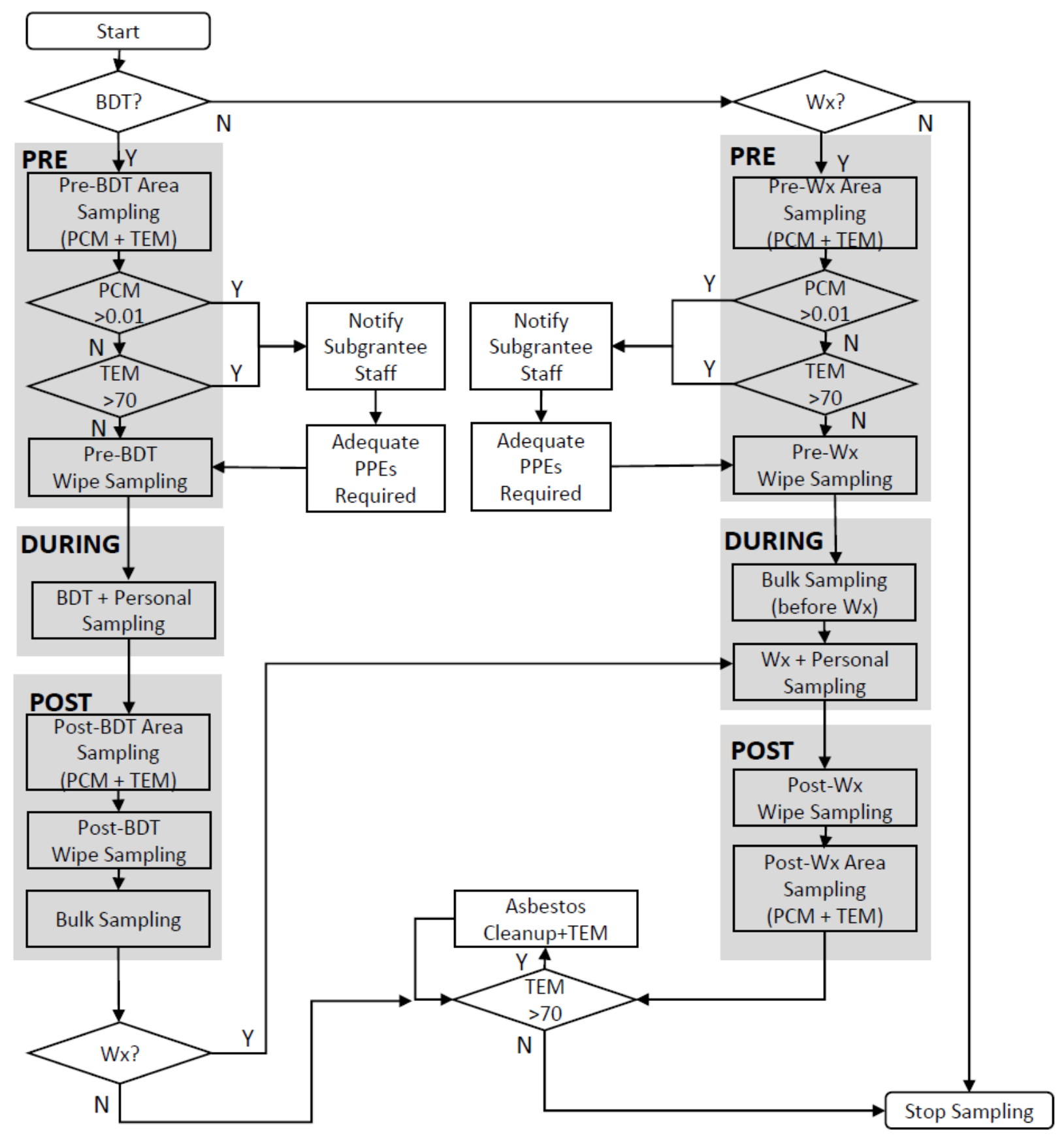

Figure 1. Flow-chart depicting the sequence of workflow of the study activities. (Note: BDT = Blower door test, $\mathrm{Wx}=$ Weatherization. PCM test results compared against $0.01 \mathrm{f} / \mathrm{cc}$ threshold, TEM test results compared against 70 structures $/ \mathrm{mm}^{2}$ threshold.) 


\section{REGULATIONS AND NECESSARY TRAININGS}

Regulations pertaining to asbestos have been promulgated by the U.S. Environmental Protection Agency (EPA) and the Occupational Safety and Health Administration (OSHA). The asbestos sampling firm chosen in each state for collecting samples will be required to comply with the accreditation and regulatory requirements of both EPA and OSHA, including any state and local asbestos requirements. State and local regulations on these issues vary and may be more stringent than federal requirements. Hence, asbestos sampling certification requirements are state-specific, although there are a lot of similarities of requirements across different states.

The U.S. EPA's National Emission Standards for Hazardous Air Pollutants (NESHAP) regulates asbestos-containing waste materials. NEHSAP establishes management practices and standards for the handling of asbestos and emissions from the waste disposal operations (40 CFR Part 61, Subparts A and M). Both 40 CFR 763 and its addendum provide comprehensive rules for the asbestos abatement industry.

OSHA regulations (29 CFR $\S 1910.1001(j)(7))$ require employers to institute and ensure participation in a worker training program for all professional employees performing job duties potentially exposing them to airborne asbestos fibers (either measured or anticipated) at or above the PEL of $0.1 \mathrm{f} / \mathrm{cc}$ for an 8-hour TWA and/or the EL of $1.0 \mathrm{f} / \mathrm{cc}$ for a 30-minute TWA. The training program consists of an initial training period, the duration of which is determined by the type of work the employee performs, and an annual refresher training. In addition, according to the EPA regulations governing schools, all school staff custodial and maintenance workers who conduct any activities that may result in the disturbance of asbestos-containing material (ACM) must receive 16 hours of operations and maintenance (O\&M) training (comprised of 2 hours of Awareness Training and 14 hours of Special O\&M Training) [36].

The OSHA standard establishes a classification system for asbestos construction work that spells out mandatory, simple, technological work practices that employers must follow to reduce worker exposures [37]. Under this system, the following four classes of construction work are matched with the respective control requirements, Class I mandating the most stringent controls, descending down to Class IV with minimal control requirements.

- Class I asbestos work is the most potentially hazardous class of asbestos jobs. This work involves the removal of asbestos-containing thermal system insulation and sprayed-on or troweled-on surfacing materials. Employers must presume that thermal system insulation and surfacing material found in pre-1981 construction is ACM. That presumption, however, is rebuttable. If you believe that the surfacing material or thermal system insulation is not ACM, the OSHA standard specifies the means that you must use to rebut that presumption. Thermal system insulation includes ACM applied to pipes, boilers, tanks, ducts, or other structural components to prevent heat loss or gain. Surfacing materials include decorative plaster on ceilings and walls; acoustical materials on decking, walls, and ceilings; and fireproofing on structural members.

- Class II work includes the removal of other types of ACM that are not thermal system insulation such as resilient flooring and roofing materials. Examples of Class II work include removal of asbestos-containing floor or ceiling tiles, siding, roofing, or Ttransite panels.

- Class III asbestos work includes repair and maintenance operations where ACM or presumed ACM (PACM) are disturbed. Only this class of asbestos work is relevant to our sampling efforts for this study.

- Class IV work includes custodial activities where employees clean up asbestos-containing waste and debris produced by construction, maintenance, or repair activities. This work involves cleaning dust-contaminated surfaces, vacuuming contaminated carpets, mopping floors, and cleaning up ACM or PACM from thermal system insulation or surfacing material. 
On all construction sites with asbestos operations, employers must designate a competent person-one who can identify asbestos hazards in the workplace and has the authority to correct them. This person must be qualified and authorized to ensure worker safety and health as required by Subpart C, General Safety and Health Provisions for Construction (29 CFR Part 1926.20). Under these requirements for safety and health prevention programs, the competent person must frequently inspect job sites, materials, and equipment. The competent person must attend a comprehensive training course for contractors and supervisors certified by the US EPA or a state approved training provider, or complete a course that is equivalent in length and content.

For the purpose of sampling necessary for this research project, we held an initial round of discussions and brainstorming sessions with asbestos professionals both internal and external to ORNL. Several professional environmental health and safety agencies were identified and listed as potential training providers for the ORNL study team to be trained in EPA and state accredited training for asbestos sampling. The training agencies were found to be providing asbestos trainings on the following disciplines under the AHERA Model Accreditation Plan [38]:

- Abatement Project Supervisor (and refresher)

- Abatement Worker (and refresher)

- Air Sampling and Analysis (NIOSH 582 Equivalent [39]) - for lab analysis

- Abatement Project Designer (and refresher)

- Asbestos Inspection and Assessment (and refresher)

- Asbestos Project Monitor (and refresher) - the only one including air sampling training

- Asbestos Management Planner (and refresher)

- Work Practices for Asbestos Operations and Maintenance (and refresher)

- Asbestos Awareness

After initial research and discussions with asbestos professionals and experts and the review of MAP training packages offered by EPA-accredited training providers, it was identified that at a minimum, the two training disciplines applicable for this research study-related sampling efforts will be:

1. Asbestos Inspection and Assessment Training: This is a 3-day training course which includes legal considerations, health effects, understanding building systems, general inspection and assessment of ACM, bulk sampling and reporting besides conducting an actual building inspection during a field exercise. Completing the course and passing the exam will guarantee a U.S. EPA AHERA accredited certification.

2. Asbestos Project Monitor Training: This is a 5-day training program meant for an individual that is responsible for on-site observation and measurements of asbestos abatement activities. The abatement project monitor is often also responsible for the collection of air samples before, during and after (final clearance) asbestos abatement.

The project coordinator and technical lead for this research study Prateek Shrestha has been trained in both these disciplines from an accredited asbestos training, contracting and consulting firm located in Nashville, Tennesse. Although abatement is not a component being considered for this study, most of the trainings available are focused around the best practices associated with abatement activities. However, the professional training courses are anticipated to be instrumental in knowing what current practices are being followed by asbestos professionals not just during an abatement process, but also during an initial inspection as well as bulk and air sampling for asbestos during weatherization of houses with ACM, in our case, vermiculite insulation. In addition, training of ORNL personnel, especially the project coordinator responsible for the experimental plan development, will ensure proper understanding of the methodologies followed by the certified personnel from accredited asbestos sampling firms in the field during sampling, and easier and effective communication with the sampling personnel. 


\section{PROJECT IMPLEMENTATION}

Implementation of this experimental plan will vary in each state depending on how WAP itself is implemented in that state, the specific vermiculite-related approaches being studied, the capabilities of the Subgrantees selected for participation in the study, the availability of a research organization to help implement the study, and other factors. An implementation plan will be developed for each state based on these factors. A general discussion of how the experimental plan will be implemented in each state is provided in the remainder of this section.

\subsection{PROJECT RESPONSIBILITIES}

ORNL will manage the study by conducting or coordinating all study activities. This includes

- Developing this experimental plan

- Selecting Grantees, Subgrantees, and houses

- Developing state-specific implementation plans

- Contracting with local asbestos sampling firms

- Procuring instrumentation (if needed)

- Training on all the field sampling and measurements to be performed

- Contracting with a commercial analytical lab

- Maintaining databases

- Performing quality checks and ensuring data quality

- Analyzing and evaluating data

- Preparing a final report to document the project and its results.

The state offices administering the WAP at the state level will assist in developing the implementation plan for their state, enlist the cooperation of the Subgrantees and assist in their selection, provide program information as needed, and help manage the study at the state level. These offices will fund Subgrantees to weatherize the study houses following their standard procedures.

The Subgrantees will assist in house selection, the identification of local accredited asbestos sampling firms (if needed), and the collection of study data depending on their capabilities and asbestos-related training/certifications. The Subgrantees will oversee communications with the occupants of the houses, including gaining their consent to participate in the study, scheduling the times to perform the vermiculite-related approaches, and distributing gift cards to the occupants for participation in the study. The subgrantees will also accompany the asbestos sampling firm to their first visit to each house and possibly each visit to every house. Finally, the Subgrantee will perform all weatherization work and/or positive-pressure blower door testing in the houses. It should be noted that the study will require a disruption in the Subgrantee's normal weatherization work flow to accommodate pre- and postweatherization testing and, in some cases, performing the vermiculite-related weatherization work (i.e., the study approaches and/or the positive-pressure blower door testing) in a non-standard time sequence. ORNL will contract with them to compensate them for their time and effort spent on implementing the study; however, the cost associated with performing the vermiculite-related weatherization work will be funded by the state.

ORNL will contract with an accredited asbestos sampling firm (preferably local to the state or region) to assist in implementing the study in a state. Their responsibilities will include coordinating with the Subgrantees in selecting and scheduling houses, collecting samples, making measurements and collecting other study data in the houses, and coordinating the shipment of samples to the accredited analytical laboratory and other data to ORNL. 


\subsection{INSTITUTIONAL REVIEW BOARD}

The study procedures will be reviewed and approved by the ORNL Institutional Review Board (IRB) before any field sampling will be performed. The IRB review process will involve risk identification to the human subjects for participating in the research, communicating the risks to the participants, communicating the procedures associated with the use of personally identifiable information, receiving informed consent from the research participants before sampling takes place, and communicating the right of research participants to withdraw participation anytime during the sampling with no penalties.

\subsection{RESEARCH SAFETY SUMMARY}

Research safety summary (RSS) will be maintained within ORNL to ensure that all research-related activities are being performed with the highest level of safety for any ORNL staff or staff hired for the study, representing our study. Detailed standard operating procedures (SOP) will be developed and the field staff will be trained accordingly, strictly adhering to the requirements set in the RSS.

\subsection{DATA HANDLING AND PROTECTION}

Research data will be handled to maintain data privacy, prevent disclosures of personally identifiable information (PII), and avoid data handling errors.

Any data with PII will first be recorded per an encryption protocol (which will be confidentially developed specifically for this project alone) to de-identify the specific house from which the data was collected. The research team will be fully aware of which house is being tested on a given day. An identification number (ID) will be pre-assigned to each house from which data is being collected and will be given to the field asbestos professionals tasked with data collection. Corresponding sample ID will be associated with each sample (bulk or air or surface) collected from each house.

Sampler IDs will be tracked thoroughly during the sample shipment and lab analysis procedures using the respective chain-of-custody forms. The results reported by the laboratories analyzing the samples will also be maintained according to the same house and sample IDs. The lab-reported values will be received via email and recorded at a secure ORNL server space dedicated solely to the research project. A back-up copy of the data will be maintained by the project coordinator in a secure external USB hard drive regularly as more data flows in with on-going data collection. Standards-Based Management System $(\mathrm{SBMS}){ }^{16}$ protocols of ORNL will be strictly followed including ORNL requirements to handle and store PIIs ${ }^{17}$.

${ }^{16} \mathrm{https}: / /$ sbms.ornl.gov/sbms/index.cfm

${ }^{17} \mathrm{https}: / /$ ornl.sharepoint.com/sites/its/Documents/PII\%20FAQ.pdf 


\section{REFERENCES}

[1] "Protect Your Family from Asbestos-Contaminated Vermiculite Insulation | Asbestos | US EPA." [Online]. Available: https://www.epa.gov/asbestos/protect-your-family-asbestos-contaminatedvermiculite-insulation. [Accessed: 19-Dec-2019].

[2] “1910.1001 App B - Detailed procedure for asbestos sampling and analysis - Non-Mandatory | Occupational Safety and Health Administration." [Online]. Available: https://www.osha.gov/lawsregs/regulations/standardnumber/1910/1910.1001AppB. [Accessed: 19-Dec-2019].

[3] R. Spirtas et al., "Malignant mesothelioma: Attributable risk of asbestos exposure," Occup. Environ. Med., vol. 51, no. 12, pp. 804-811, 1994.

[4] A. Lacourt et al., "Occupational and non-occupational attributable risk of asbestos exposure for malignant pleural mesothelioma," Thorax, vol. 69, no. 6, pp. 532-539, 2014.

[5] J. M. Hughes and H. Weill, "Asbestos Exposure - Quantitative Assessment of Risk," Am. Rev. Respir. Dis., vol. 133, no. 1, pp. 5-13, Jan. 1986.

[6] J. Peto, H. Seidman, and I. J. Selikoff, "Mesothelioma mortality in asbestos workers: Implications for models of carcinogenesis and risk assessment," Br. J. Cancer, vol. 45, no. 1, pp. 124-135, 1982.

[7] T. Uibu et al., "Asbestos exposure as a risk factor for retroperitoneal fibrosis," Lancet, vol. 363, no. 9419, pp. 1422-1426, May 2004.

[8] G. P. Meeker et al., "The composition and morphology of amphiboles from the Rainy Creek complex, near Libby, Montana," Am. Mineral., vol. 88, no. 11-12 PART 2, pp. 1955-1969, Nov. 2003.

[9] “ASBESTOS (CHRYSOTILE, AMOSITE, CROCIDOLITE, TREMOLITE, ACTINOLITE AND ANTHOPHYLLITE) - Arsenic, Metals, Fibres and Dusts - NCBI Bookshelf.” [Online]. Available: https://www.ncbi.nlm.nih.gov/books/NBK304374/. [Accessed: 05-Mar-2020].

[10] "Weatherization Assistance Program | Department of Energy." [Online]. Available: https://www.energy.gov/eere/wipo/weatherization-assistance-program. [Accessed: 19-Dec-2019].

[11] "General Information - Zonolite Attic Insulation Trust." [Online]. Available: https://www.zonoliteatticinsulation.com/s/General-Information. [Accessed: 18-Mar-2020].

[12] Asbestos Model Accreditation Plan for States. pp. 901-916.

[13] "Electronic Code of Federal Regulations: 40 CFR Part 763 - Asbestos." [Online]. Available: https://www.ecfr.gov/cgi-bin/text-idx?tpl=/ecfrbrowse/Title40/40cfr763_main_02.tpl. [Accessed: 13-Apr-2020].

[14] “1910.134 - Respiratory Protection. | Occupational Safety and Health Administration.” [Online]. Available: https://www.osha.gov/laws-regs/regulations/standardnumber/1910/1910.134.

[Accessed: 14-Oct-2020].

[15] "NIOSH guide to the selection and use of particulate respirators certified under 42 CFR 84.," Jan. 1996.

[16] "1910.120 - Hazardous waste operations and emergency response. | Occupational Safety and Health Administration.” [Online]. Available: https://www.osha.gov/lawsregs/regulations/standardnumber/1910/1910.120. [Accessed: 14-Oct-2020].

[17] "EPA 560/5-85-024 Guidance for Controlling Asbestos-Containing Materials in Buildings."

[18] “Asbestos - 1926.1101 | Occupational Safety and Health Administration.” [Online]. Available: 
https://www.osha.gov/pls/oshaweb/owadisp.show_document?p_id=10862\&p_table=standards. [Accessed: 15-Oct-2020].

[19] “1910.1001 App A - OSHA Reference Method - Mandatory | Occupational Safety and Health Administration.” [Online]. Available: https://www.osha.gov/lawsregs/regulations/standardnumber/1910/1910.1001AppA. [Accessed: 15-Oct-2020].

[20] T. M. Spear, J. F. Hart, T. E. Spear, M. M. Loushin, N. N. Shaw, and M. I. Elashhab, "The Presence of Asbestos-Contaminated Vermiculite Attic Insulation or Other Asbestos-Containing Materials in Homes and the Potential for Living Space Contamination," Journal of Environmental Health, vol. 75. National Environmental Health Association (NEHA), pp. 24-29, 2012.

[21] K. Ashley, G. T. Applegate, T. J. Wise, J. E. Fernback, and M. J. Goldcamp, "Evaluation of a Standardized Micro-Vacuum Sampling Method for Collection of Surface Dust," J. Occup. Environ. Hyg., vol. 4, no. 3, pp. 215-223, Mar. 2007.

[22] K. Santee and P. F. Lott, "Asbestos Analysis: A Review," Applied Spectroscopy Reviews, vol. 38, no. 3. pp. 355-394, Aug-2003.

[23] N. Shaw, "Comparison of Wet Wipe vs Micro-Vacuum Sampling Techniques for Determining Concentrations of Asbestos in Surface Dust."

[24] J. R. Kominsky and J. R. Millette, "Evaluation of Asbestos in Dust on Surfaces by Micro-Vacuum and Wipe Sampling,” 2011.

[25] J. R. Millette and S. Compton, "Analysis of Vermiculite for Asbestos and Screening for Vermiculite from Libby, Montana," Microsc., vol. 63, no. 2, pp. 59-75, 2015.

[26] "Method 6010D Inductively Coupled Plasma - Optical Emission Spectrometry." [Online]. Available: https:/www.epa.gov/sites/production/files/2015-12/documents/6010d.pdf. [Accessed: 03-Nov-2020].

[27] "40 CFR Appendix A to Subpart E of Part 763 - Interim Transmission Electron Microscopy Analytical Methods - Mandatory and Nonmandatory - and Mandatory Section To Determine Completion of Response Actions | CFR | US Law | LII / Legal Information Institute." [Online]. Available: https://www.law.cornell.edu/cfr/text/40/appendix-A_to_subpart_E_of_part_763. [Accessed: 04-May-2020].

[28] CDC and Niosh, "NIOSH Manual of Analytical Methods (NMAM), Fifth Edition ASBESTOS and OTHER FIBERS by PCM 7400," 1989.

[29] “ASBESTOS by TEM 7402,” Aug. 1994.

[30] ASTM, "Standard Test Method for Microvacuum Sampling and Indirect Analysis of Dust by Transmission Electron Microscopy for Asbestos Structure Number Surface Loading," vol. i, no. Reapproved 2014, pp. 1-15, 2006.

[31] "Vermiculite - LABCOR INC." [Online]. Available: http://www.labcor.net/vermiculite.html. [Accessed: 03-Jun-2020].

[32] "Specialized Asbestos Testing | SGS Galson." [Online]. Available: https://www.sgsgalson.com/asbestos-testing/. [Accessed: 03-Jun-2020].

[33] M. E. Gunter, E. Singleton, B. R. Bandli, H. A. Lowers, and G. P. Meeker, "Differentiation of commercial vermiculite based on statistical analysis of bulk chemical data: Fingerprinting vermiculite from Libby, Montana U.S.A," Am. Mineral., vol. 90, no. 4, pp. 749-754, Apr. 2005.

[34] “ASTM D6480 - 19 Standard Test Method for Wipe Sampling of Surfaces, Indirect Preparation, and Analysis for Asbestos Structure Number Surface Loading by Transmission Electron 


\section{Microscopy."}

[35] "Montana Asbestos-Safe Weatherization Demonstration Project," 2010.

[36] O. US EPA, “Asbestos Training."

[37] “Asbestos Standard for the Construction Industry." [Online]. Available: https://www.osha.gov/Publications/OSHA3096/3096.html. [Accessed: 27-Dec-2019].

[38] “The Environmental Institute." [Online]. Available: http://www.teiatl.com/courses/courses.asp?catid=1\#6. [Accessed: 27-Dec-2019].

[39] "Sampling and evaluating airborne asbestos dust (582)." [Online]. Available: https://www.cdc.gov/niosh/nioshtic-2/00148459.html. [Accessed: 16-Oct-2020]. 


\section{APPENDIX A. PRE-WEATHERIZATION ACTIVITY WALKTHROUGH SURVEY}

Table AA 1. Pre-weatherization activity walkthrough survey questionnaire (to be filled out by Subgrantee representative).

ORNL Vermiculite Study: Building Characteristics (House Walkthrough) Survey

House ID:

Date and time:

Field Tech ID:

Field conditions (check all that apply): $\square$ Sunny $\square$ Cloudy $\square$ Calm $\square$ Windy $\square$ Rainy $\square$ Snowy

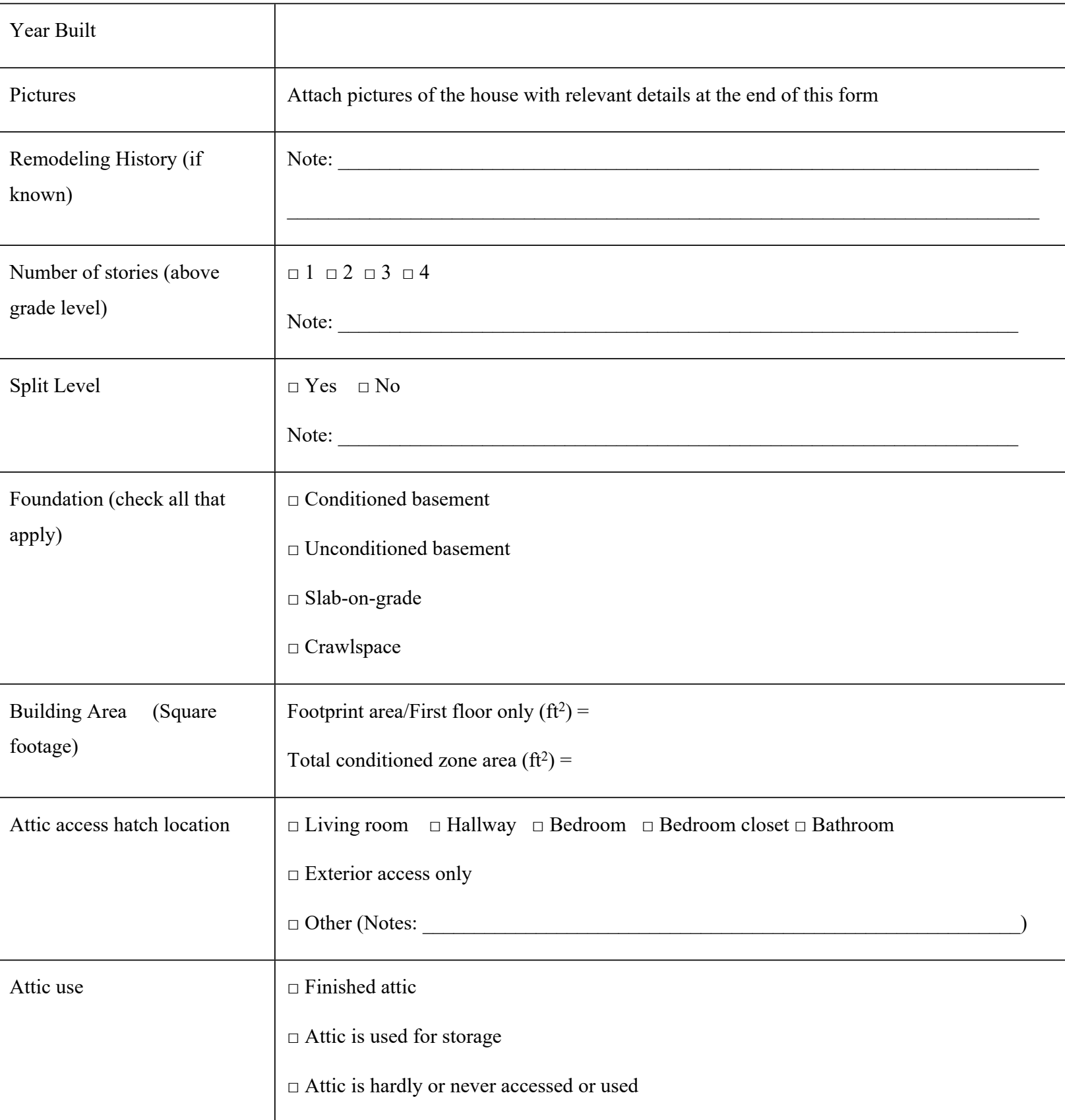




\begin{tabular}{|c|c|}
\hline & $\square$ Other (Notes: \\
\hline Attic venting & $\begin{array}{l}\square \text { Powered attic fans } \\
\square \text { Passive attic turbine-driven fans (wind driven) } \\
\square \text { Passive attic venting (Circle the types of vents present: gable/ridge/soffit/roof vent) } \\
\square \text { Other (Notes: }\end{array}$ \\
\hline $\begin{array}{l}\text { Heating/Cooling System } \\
\text { (Check all that apply): }\end{array}$ & $\begin{array}{l}\square \text { Gas/oil furnace with integrated air conditioning (A/C) } \\
\square \text { Gas/oil furnace and no A/C } \\
\square \text { Gas/oil boiler with radiators in the rooms } \\
\square \text { Electric baseboard heating } \\
\square \text { Central heat pump (heating/cooling) } \\
\square \text { Window heat pump } \\
\square \text { Window A/C } \\
\square \text { Swamp (evaporative) cooler } \\
\square \text { Wood burning stove } \\
\square \text { Space heaters (fossil fuel) } \\
\square \text { Electric space heaters } \\
\square \text { Electric furnace with A/C } \\
\square \text { Electric furnace without A/C } \\
\square \text { Fireplace (Circle one if present: Gas / Electric / Wood burning ) } \\
\square \text { Other (Notes: }\end{array}$ \\
\hline $\begin{array}{l}\text { Mechanical Ventilation Type } \\
\text { (Check all that apply) }\end{array}$ & $\begin{array}{l}\square \text { Continuous whole house exhaust fan (Location: } \\
\square \text { Bathroom exhaust fans (user operated) } \\
\square \text { Kitchen exhaust fan (user operated) } \\
\square \text { HRV or ERV system (dedicated outdoor air ventilation system) } \\
\square \text { Fans/Mechanical Ventilation Absent } \\
\text { Notes : }\end{array}$ \\
\hline Furnace Ductwork Location & $\square$ Attic \\
\hline
\end{tabular}




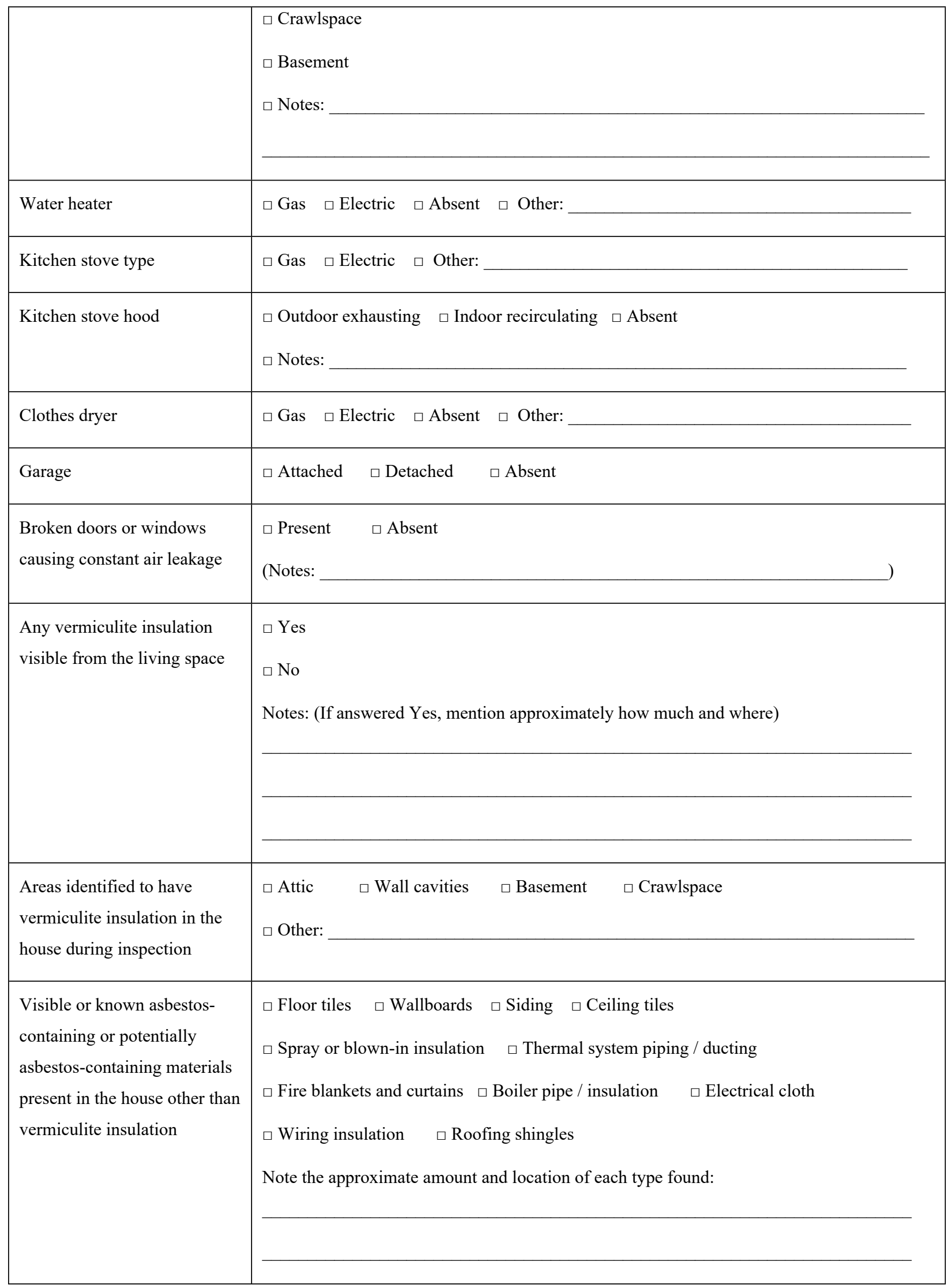




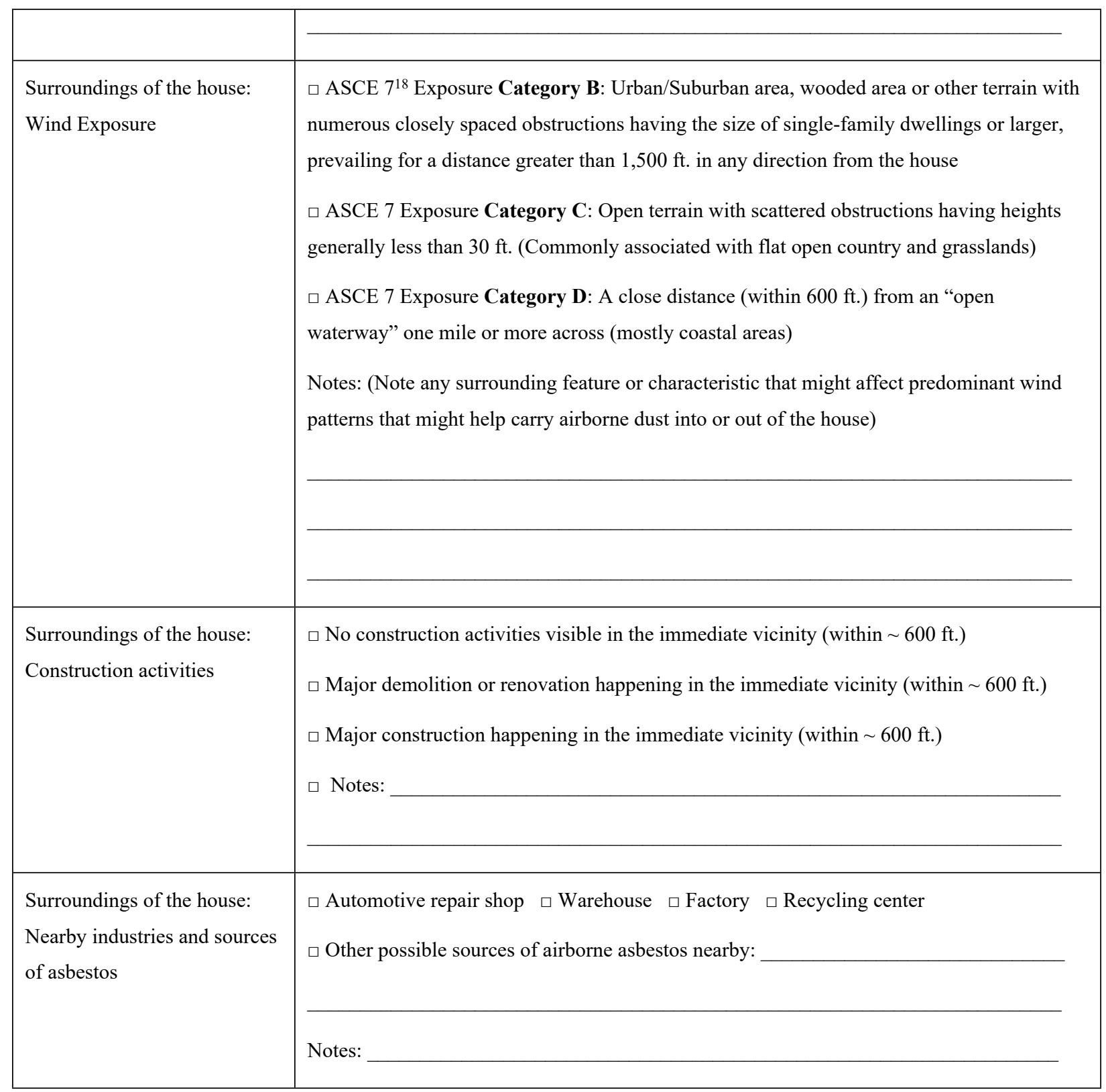

\footnotetext{
${ }_{18}$ American Society of Civil Engineers Standard ASCE 7, "Minimum Design Loads and Associated Criteria for Buildings and Other Structures (ASCE/SEI 7-16)", available online at: https://www.dasma.com/PDF/Publications/TechDataSheets/CommercialResidential/TDS193.pdf (Note: Exposure Category A was deleted. Previously Exposure A was intended for heavily built up city centers with tall buildings but it was later decided that in areas with clost proximity to tall buildings the variability of the wind is too great, because of local channeling and wake buffeting effects, to allow a special category A to be defined: https://www.engineeringexpress.com/wiki/asce-7-exposure-d-work/)
} 
Table AA 2. House layout skech (to be filled out by the asbestos sampling firm data collector). Instructions: Draw with a freehand sketch an approximate layout (floor plan) of the different floors of the house (can be a not-to-scale drawing), identifying where the different samples were taken. Use the symbols shown in the right hand side of the drawing area for the various sample types. Use multiple sheets if necessary. Take photographs of the areas that are wipe-sampled, avoiding to photograph any item that can be associated with PIIs.

\begin{tabular}{|c|c|c|}
\hline \multirow[t]{6}{*}{ Drawing(s): } & $\mathrm{N}$ & $\begin{array}{l}\text { Symbols to use for } \\
\text { different sample types: }\end{array}$ \\
\hline & & $\boldsymbol{\beta}$ : Bulk sampling \\
\hline & & $\begin{array}{l}\boldsymbol{\sigma}: \text { Personal sampling } \\
\text { (since person with this type } \\
\text { of sampling will be moving } \\
\text { around, denote the } \\
\text { approximate perimeter of } \\
\text { the area he/she will move } \\
\text { around in with a dotted line } \\
\text { (- - -) and show one or } \\
\text { more } \boldsymbol{\sigma} \text { symbols lying } \\
\text { within and adjacent to the } \\
\text { dotted line. }\end{array}$ \\
\hline & & $\omega$ : Wipe sampling \\
\hline & & $\begin{array}{l}\boldsymbol{\pi}: \text { Area sampling } \\
\text { (NIOSH } 7400 \text { Method) }\end{array}$ \\
\hline & & $\begin{array}{l}\tau: \text { Area sampling (EPA } \\
\text { AHERA Method) }\end{array}$ \\
\hline
\end{tabular}

Notes: 


\section{APPENDIX B. POST-WEATHERIZATION ACTIVITY SURVEY}

Table AB 1. Post-weatherization activity survey questionnaire (to be filled out by the Subgrantee representative).

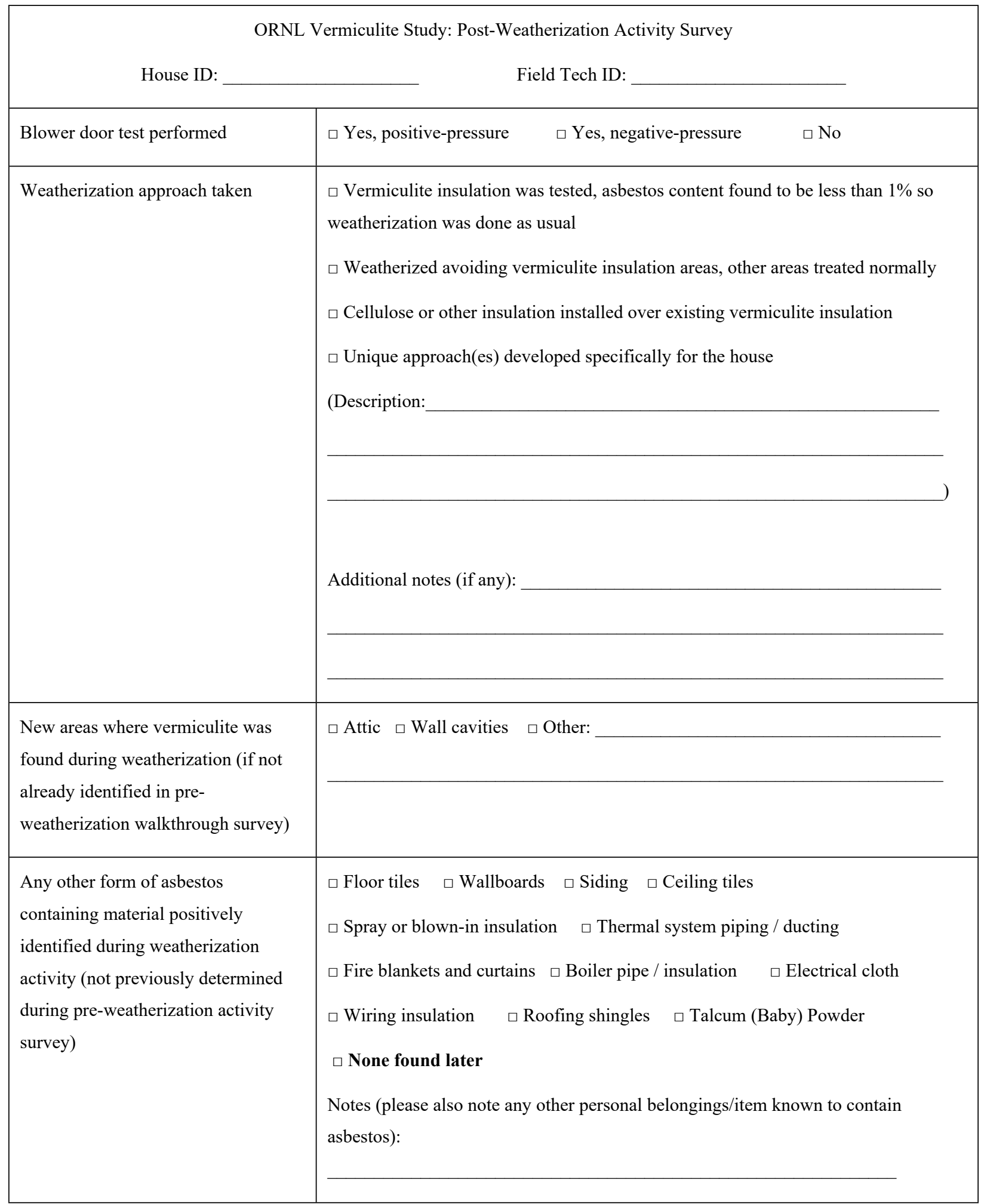




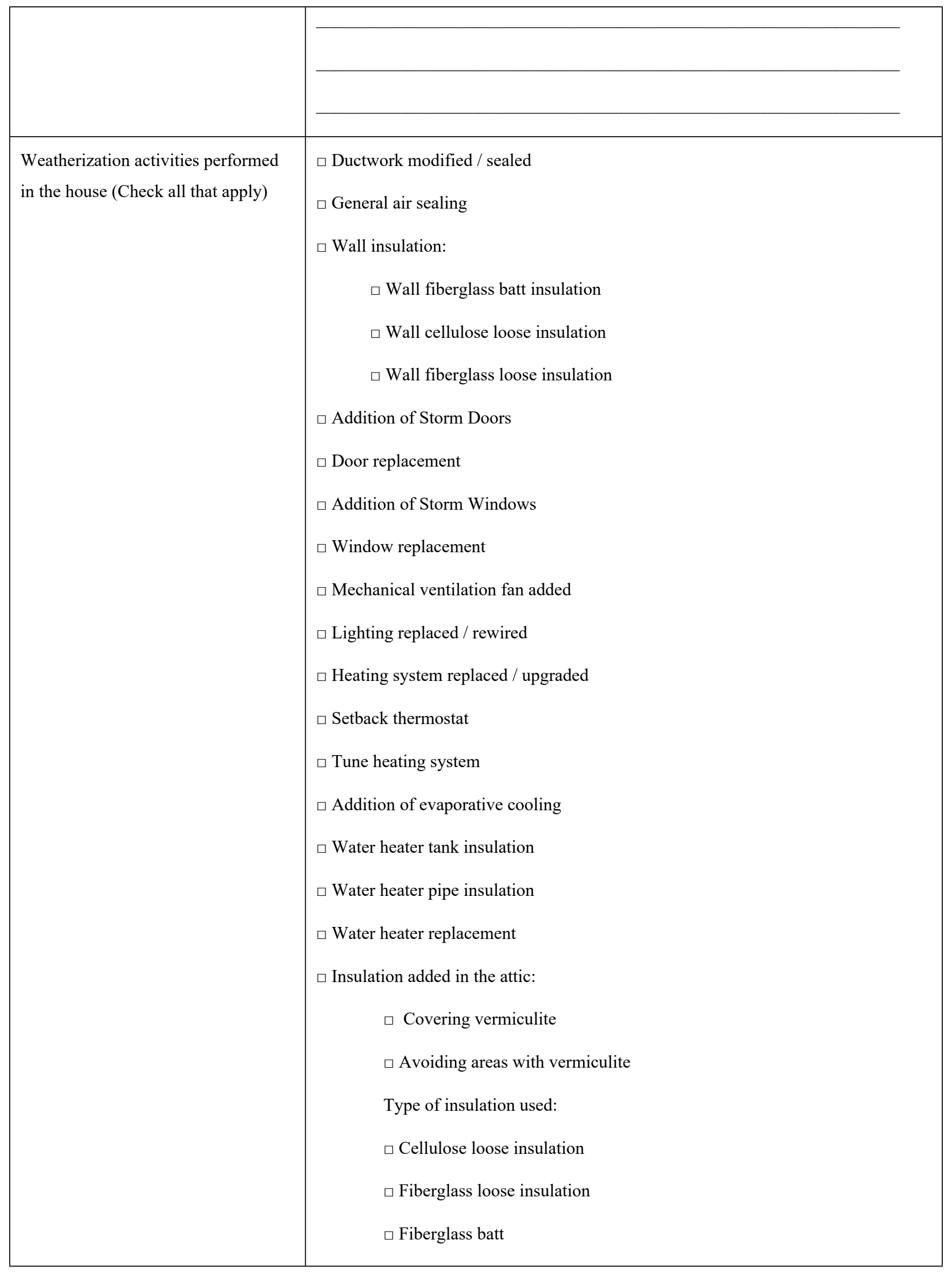




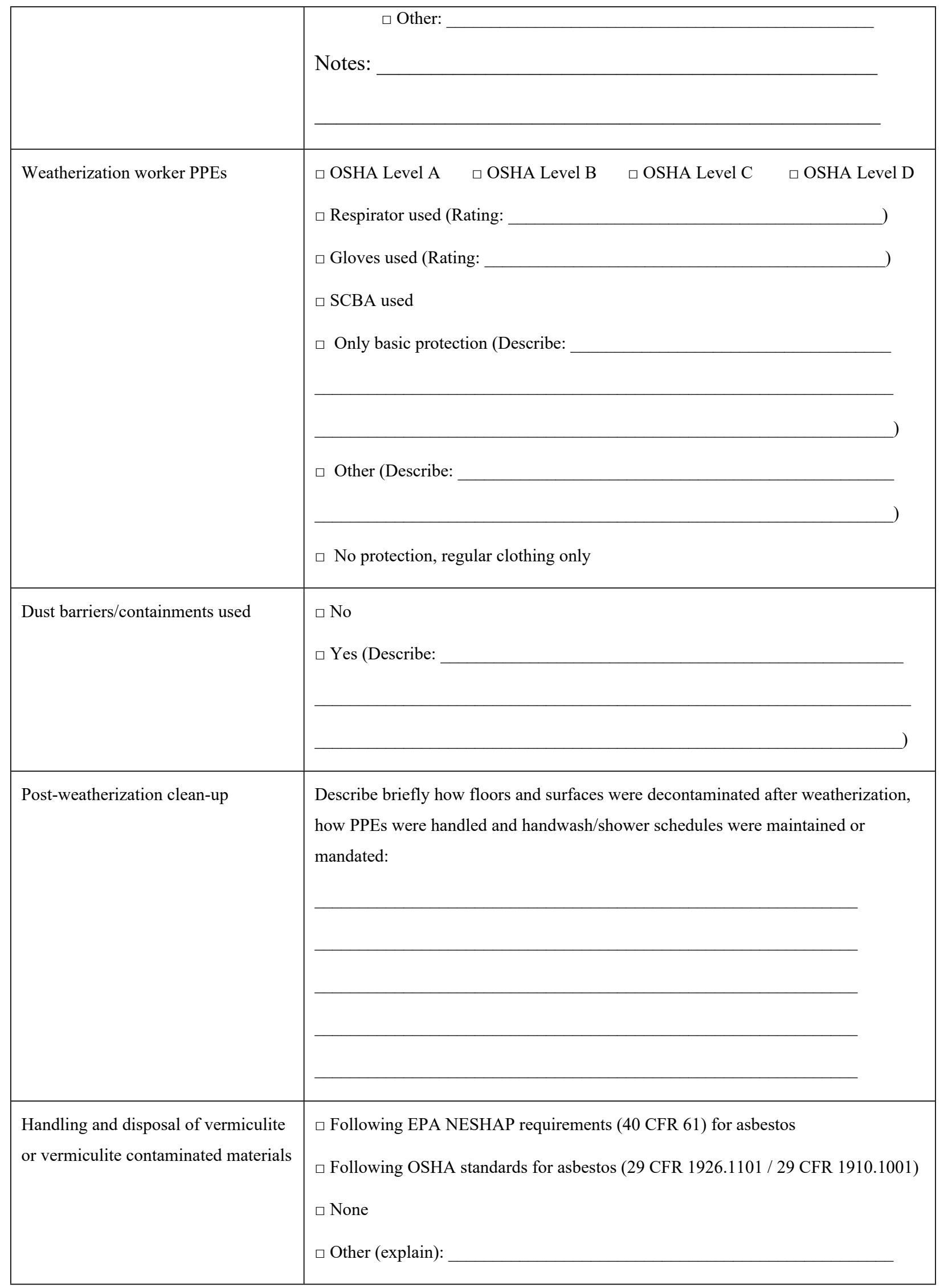




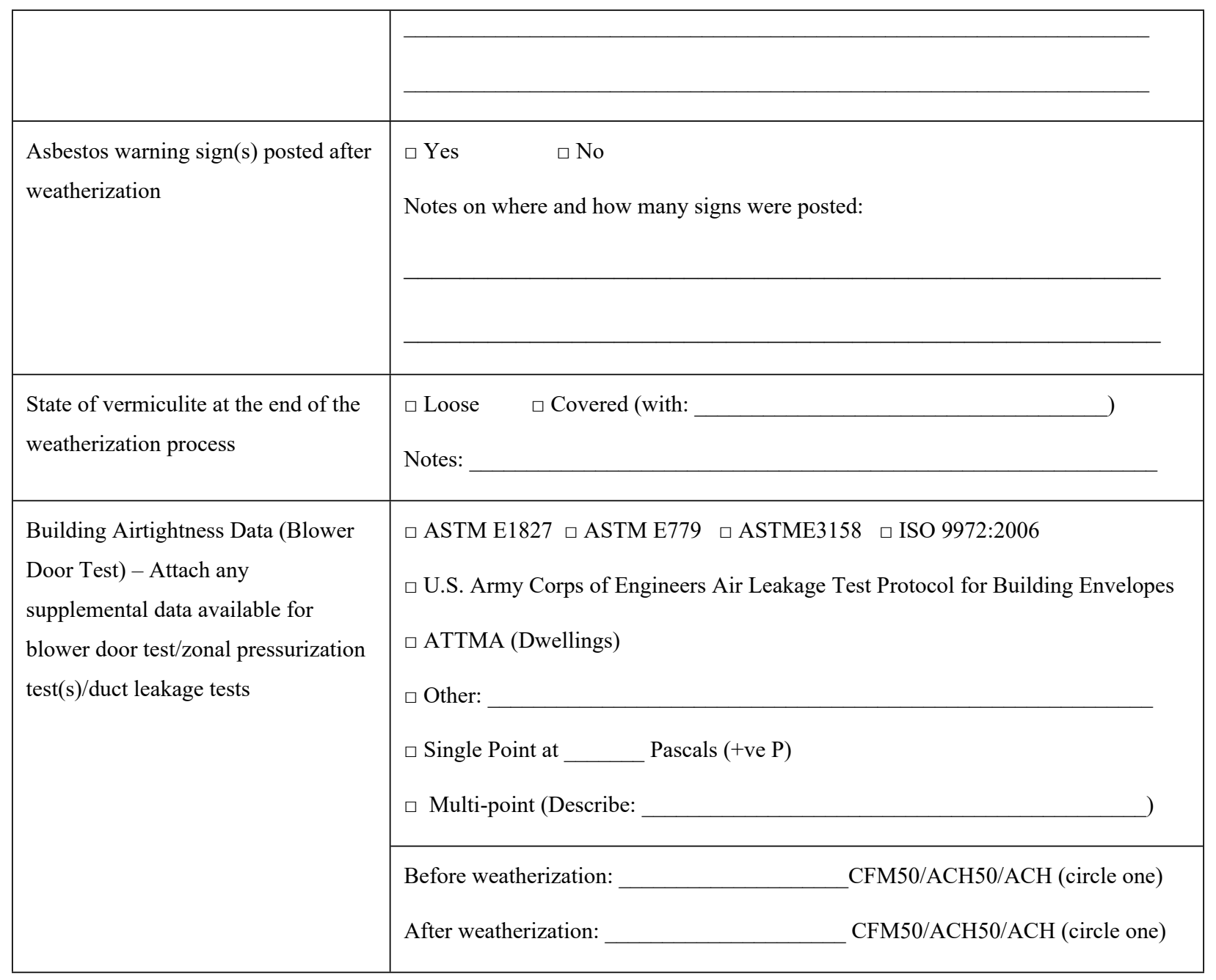




\section{APPENDIX C. SAMPLE NOMENCLATURE AND SAMPLE ID FORM}

Before dispatching equipment to the field for sampling, each sampler will be labelled by the data collector to identify the house ID, date of sampling, type of sample and location of sampling. The naming convention followed will be as follows:

\section{AA-XXX-aaaAX-XXXXXX}

(A denoting capital letter, a denoting small letters and $\mathbf{X}$ denoting digits) to designate

$$
\text { (State) - (House ID) - (Sample ID) - (Date) }
$$

For example:

\section{WI-042-preA1-071220}

Designates:

WI: The state of Wisconsin

042: House ID (assigned in chronological order of the houses enrolled in the study). This would be the $42^{\text {nd }}$ house enrolled in the study.

pA1: A 'pre' occurring as a prefix denotes pre-weatherization sample. Similarly, a 'post' occurring as a prefix denotes a post-weatherization sample. The letter in capital denotes the type of sample: 'A' denoting area sample, 'B' denoting bulk sample, 'P' denoting personal air monitoring sample, and ' $\mathrm{W}$ ' denoting wipe sample. Following the capital letter, the number denotes the individual sample number. For example, if more than one location is being sampled for area sample, the first sample would be A1, the second one would be A2, and so on.

071220: Date in $M M / D D / Y Y$ format

After assigning the Sample ID, the Sample ID form should be filled out (see Table AC 1 below). 
Table AC 1. Sample ID form for Bulk and Wipe Samples

(To be filled out by the asbestos sampling firm data collector, use as many sheets as needed)

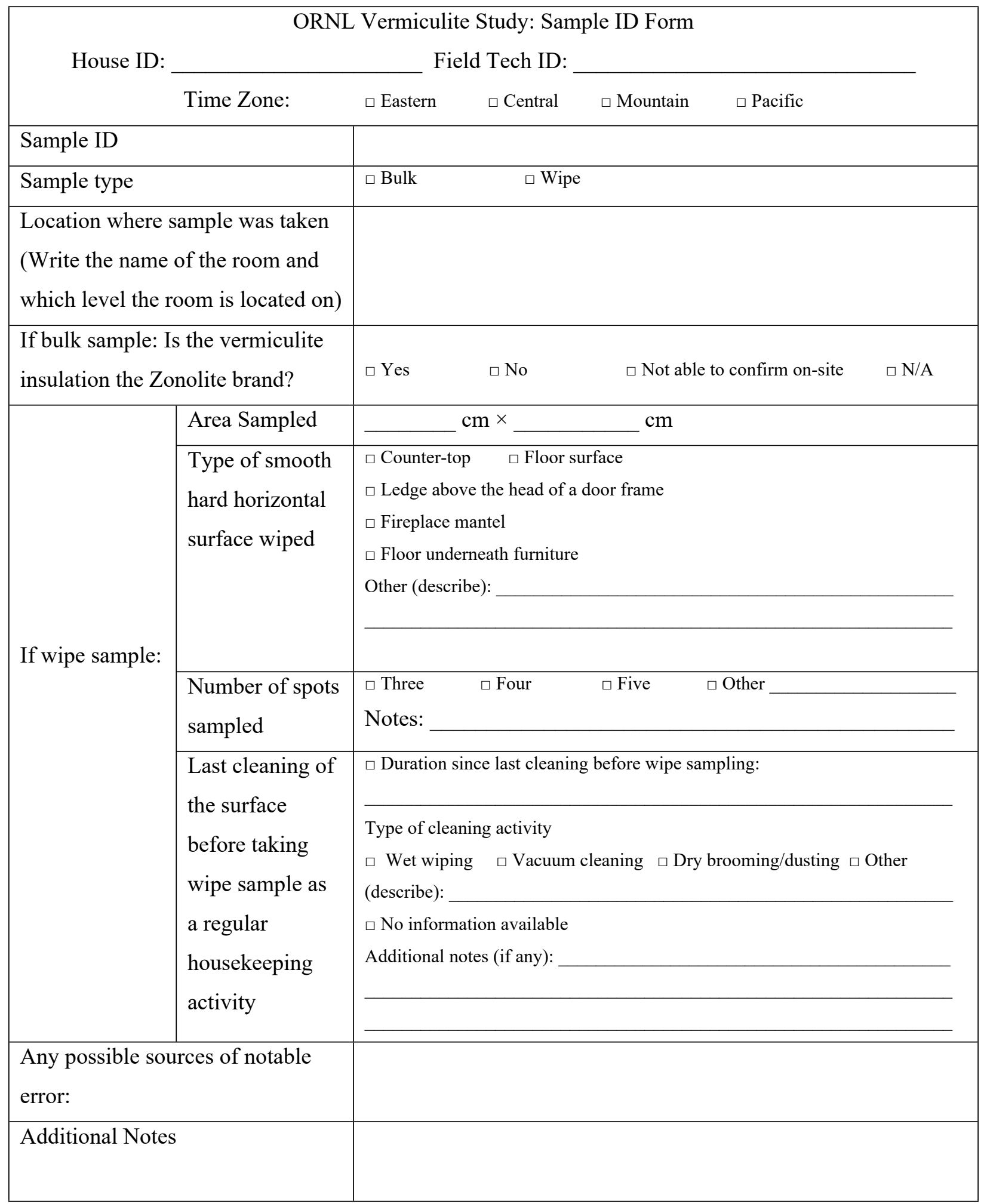


Table AC 2. Sample ID form for Personal and Area Samples

(To be filled out by the asbestos sampling firm data collector, use as many sheets as needed)

\begin{tabular}{|c|c|}
\hline \multicolumn{2}{|r|}{ ORNL Vermiculite Study: Sample ID Form } \\
\hline \multirow{2}{*}{ House ID: } & Field Tech ID: \\
\hline & $\square$ Eastern $\quad \square$ Central $\quad \square$ Mountain \\
\hline \multicolumn{2}{|l|}{ Sample ID } \\
\hline Sample type & $\square$ Personal $\quad \square$ Area \\
\hline \multicolumn{2}{|l|}{$\begin{array}{l}\text { Location where sample was } \\
\text { taken (Write the name of the } \\
\text { room and which level the room } \\
\text { is located on) }\end{array}$} \\
\hline Start time & 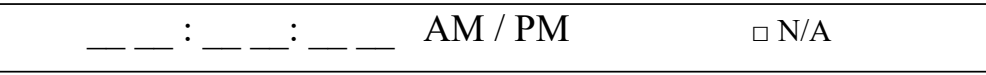 \\
\hline Stop time & $-\_: \_\_$_ - AM / PM $\quad \square$ N/A \\
\hline $\begin{array}{l}\text { Air flow rate calibration } \\
\text { performed } \\
\text { for pump }\end{array}$ & $\begin{array}{l}\text { NIST-traceable primary flow calibration device: } \\
\text { NIST-traceable flow calibrator type (include make/model): } \\
\text { Flow rate set point (lpm) }= \\
\text { NIST-traceable flow calibrator flow rate }= \\
\square \text { No information available on NIST-traceable primary flow calibrator } \\
\text { - Secondary flow calibration device: } \\
\quad \text { Secondary flow calibrator type (include make/model): } \\
\text { Flow rate adjustment for secondary calibration device against } \\
\text { NIST-traceable primary flow calibrator (how much was the } \\
\text { secondary flow measurement device off by compared to the } \\
\text { primary): } \\
\square \text { Check this box to indicate that the flow offset for the secondary flow } \\
\text { measurement device was applied to the collected data. }\end{array}$ \\
\hline \multirow{2}{*}{$\begin{array}{l}\text { Air flow rates during data } \\
\text { collection }\end{array}$} & Initial flow rate set point just before sampling $(\mathrm{lpm})=$ \\
\hline & Final flow rate at the end of sampling period $(\mathrm{lpm})=$ \\
\hline \multicolumn{2}{|l|}{ Total volume of air sampled (1) } \\
\hline \multicolumn{2}{|l|}{$\begin{array}{l}\text { Any possible sources of notable } \\
\text { error: }\end{array}$} \\
\hline Additional Notes & \\
\hline
\end{tabular}




\section{APPENDIX D. SAMPLING PROCEDURES FOR WIPE SAMPLING}

The process includes wiping a surface of a known area with a wipe material to collect a sample. The following apparatus will be required for sampling:

1. Disposable wet towels

2. Masking tape

3. Measuring tape

4. Powderless rubber gloves

5. Sample container (clean, sealable, used for transporting samples to the laboratory)

6. Template to delineate sampling area: a reusable or disposable template of non-particle shedding material, such as aluminum, plastic or non-shedding cardboard. A variety of shapes (for example square, rectangular) are acceptable. All templates should have accurately known inside dimensions. Templates should be thin (less than $1 / 8$ in. or $3 \mathrm{~mm}$ ) and capable of lying flat on a flat surface. Clean reusable template before and after each use with a suitable cleaning method, such as surfactant solution or particle-free disposable wipe.

7. Wet wipe: A particle free, sealed edge, continuous filament cloth sampling medium (also commonly known as clean room wiper)

The sampling procedure involves the following steps:

1. Identify and document all areas to be sampled. Documentation should include:

- General sampling site description

- Address and city/state location

- Sample location, which should include all information needed to locate the room and where the sample was collected. These include building, floor, room number and room name.

- Surface type, which should include descriptors of the surfaces in the room upon which the samples were collected. These include floor, wall, ceiling, top of light fixture, top of ceiling tile, exterior or duct, and so forth. It is sometimes useful to provide a section allowing for identification of surface sampled (for example, for a louver, whether the sample is from the top or bottom surface; for a grill, whether the sample is from the upstream or downstream side).

- Surface material, which should describe the material from which the surface is constructed (for example, painted, plaster or drywall, wood, concrete, metal, brick, resilient flooring, and so forth).

- Surface description, which should describe the nature of the surface (for example color, texture, clean, dry, greasy, wet).

- The area of surface wiped. It may not always be possible to collect from $100 \mathrm{~cm}^{2}$ of surface. For example, one should indicate whether the effective surface area of a grill is discounted for the open spaces in the grill.

- Post sampling cleanliness of surface. A visual evaluation of the cleanliness of the surface postsampling should be made and recorded. This evaluation should not be made until the surface has dried.

2. Two sampling procedures can be followed: (1) for sampling in unrestricted areas such as floors (Template Assisted Sampling Procedures); and (2) The Confined Area Sampling Procedure. The 
Confined Area Sampling Procedure (CASP) should only be used when the Template Assisted Sampling Procedure (TASP) cannot be used due to sampling location constraints. The CASP assumes the width of the sampling location is no larger than the dimensions of a wipe. If this is not true, then the TASP is used.

\section{Template Assisted Sampling Procedure (TASP) - Preferred method}

1. If a reusable template is used, clean template with a moist wipe and discard this wipe.

2. Place template onto the surface to be sampled and attach the outer edge of the template to the surface using masking tape. Document the location and area $\left(\mathrm{cm}^{2}\right)$ of surface to be sampled. A typical sampling area is $100 \mathrm{~cm}^{2}$. Smaller or larger areas may be sampled depending on surface cleanliness.

3. Put on a pair of clean, powderless rubber gloves.

4. Adequately moisten the wipe with a 50/50 mixture of alcohol and water. For example, 10 to $20 \mathrm{~mL}$ will adequately moisten a 21 by $21-\mathrm{cm}$ wipe. It is recommended that a portion of the wipe be tested with the mixture if there is any doubt that the solvent may damage the wipe material.

5. First Wiping (side to side): Hold one edge of the wipe between the thumb and forefinger, draping the wipe over the fingers of a gloved hand. Hold fingers together, hand flat, and wipe the selected surface area, starting at either corner furthest away from the operator (referred to as a far corner), and use a slow side to side (left to right or right to left) sweeping motion. During wiping, apply even pressure to the fingertips.

6. At the end of the first side to side pass, turn the wipe's leading edge (portion of the wipe touching the surface) $180^{\circ}$. Pull the wipe path slightly close to the operator and make the second side to side pass in the reverse direction, slightly overlapping the first pass. The $180^{\circ}$ turn is used to ensure that the wiping motion is always performed in the same direction on the wipe to maximize sample pickup. Continue to cover the sampling area within the template, using the slightly overlapping side to side passes with the $180^{\circ}$ turns at each edge until the close corner of the template is reached. Carefully lift the sampled material into the wipe, using a slight rolling motion of the hand to capture the sample inside the wipe. Fold the wipe in half with the sample folded inside the fold.

7. Second Wiping (top to bottom): After folding and using a clean side of the wipe, perform a second wiping over the sampling area within the template, starting from a far corner in the same manner used for the first wiping, except use a top to bottom sweeping of the surface. When the close corner of the template is reached, carefully lift the sampled material into the wipe, using a slight rolling motion of the hand to capture the sample inside the wipe. Fold the wipe in half again, with the sample from this second wiping folded inside the fold.

8. Third Wiping (clean corners): After another fold and using a clean side of the wipe, perform a third wiping around the perimeter of the sampling area within the template. Start from one edge of the template and use the same wiping technique as described in $\# 8$ above. When the interior perimeter has been wiped and the starting location reached, carefully lift the sampled material into the wipe, using a slight rolling motion of the hand to capture the sample inside the wipe. Fold the wipe in half one more time, with the sample from this third wiping folded inside the fold.

9. Insert the folded wipe into a sample container and seal. Label the container with procedures described in Appendix C.

10. Discard gloves after each sampling activity.

11. Check that all sampling information sheets are completed and that all pertinent information has been enclosed before transferring the samples to the laboratory.

12. Collect a field blank wipe. 
13. Wipe off the exterior surface of the sample containers with disposable wet towels prior to packaging for shipment. Label the samples per Appendix $\mathrm{C}$ and send the samples to the analytical laboratory with COC forms attached.

\section{Confined Area Sampling Procedure (CASP)}

1. Put on a pair of clean, powderless rubber gloves

2. Adequately moisten the wipe with a 50/50 mixture of alcohol and water. (For example, 10 to $20 \mathrm{~mL}$ will adequately moisten a 21 by $21-\mathrm{cm}$ wipe.) It is recommended that a portion of the wipe be tested with the mixture if there is any doubt that the solvent may damage the wipe material.

3. First Wiping, One Direction, Side-to-Side-Hold one edge of the wipe between the thumb and forefinger, draping the wipe over the fingers of a gloved hand. Hold fingers together, hand flat, and wipe the selected surface area. Start at either corner furthest away from the operator (referred to as a far corner), and use a slow side to side (left to right or right to left) sweeping motion. During wiping, apply even pressure to the fingertips. At the end of the first pass from one side to the other, carefully lift the sample material into the wipe, using a slight rolling motion of the hand to capture the sample inside the wipe. Fold the wipe in half with the sample folded inside the fold

4. Second Wiping, One Direction, Side-to-Side-Using a clean side of the wipe, repeat step 3, using a wiping motion in the reverse direction. When the close corner of the sampling area is reached, carefully lift the sampled material into the wipe, using a slight rolling motion of the hand to capture the sample inside the wipe. Fold the wipe in half again, with the sample from this second wiping folded inside the fold.

5. Third Wiping, Clean Corners - Using a clean side of the wipe, perform a third wiping around the interior perimeter of the sampling area. Start from the middle of one edge of an area and use the same wiping technique as described in \#3. When the perimeter has been wiped and the starting location reached, carefully lift the sample material into the wipe, using a slight rolling motion of the hand to capture sample inside the wipe. Fold the wipe in half one more time with the sample from this third wiping folded inside the fold.

6. Insert the folded wipe into a sample container and seal. Label the sample container with procedures mentioned in Appendix C.

7. Mark the perimeter of the area just wiped lightly with a pencil or dry-erase marker.

8. Using a tape measure, measure the dimension of the sampled surface.

9. Make sure that nobody touches or disturbs this wipe sampling area until the post-weatherization wipe sampling is performed.

10. Repeat the wipe sampling after the weatheization activity is over.

11. Check that all sampling information sheets are completed and that all pertinent information has been enclosed before transfer of the sample to the laboratory

12. Collect a field blank wipe

13. Wipe off the exterior surface of the sample transport containers with a disposable wet towel prior to packaging for shipment. 